\title{
No negative impact of word retraining on vocabulary use or clarity of communication in Semantic Dementia
}

\author{
Sharon A. Savage ${ }^{1}$,Leonie F. Lampe $e^{2,3}, \&$ Lyndsey Nickels ${ }^{2}$
}

1. School of Psychological Sciences, The University of Newcastle, Callaghan, Australia

2. Department of Cognitive Science, Macquarie University, Sydney, Australia

3. International Doctorate for Experimental Approaches to Language and Brain (IDEALAB), Universities of Groningen (NL), Potsdam (DE), Newcastle (UK) and Macquarie University, Sydney (AU)

This article has been accepted for publication in Neuropsychological Rehabilitation, published by Taylor \& Francis

\begin{abstract}
Author note
Sharon A. Savage: https://orcid.org/0000-0002-6477-5222

Leonie F. Lampe: https://orcid.org/0000-0001-6020-8506

Lyndsey Nickels: https://orcid.org/0000-0002-0311-3524
\end{abstract}

Funding details: This work was supported by the Cross Program Support Scheme of the Australian Research Council Centre of Excellence in Cognition and its Disorders (\#CE110001021).

Corresponding author: Sharon A. Savage, School of Psychological Sciences, The University of Newcastle, University Drive, Callaghan, NSW 2308 Australia, sharon.savage@newcastle.edu.au

Word count: 10114 (excluding Abstract, References, and Appendices) 


\begin{abstract}
Word retraining techniques can improve picture naming of treated items in people with semantic dementia (SD). The utility of this, however, has been questioned given the propensity for under- and overgeneralisation errors in naming in SD. Few studies have investigated the occurrence of such errors. This study examined whether, following tailored word retraining: 1) misuse of words increases, 2) the type of naming errors changes, and/or 3) clarity of communication is reduced. Performance on trained and untrained word naming from nine participants with SD who completed a word retraining program were analysed. Responses from baseline and post-intervention assessments were coded for misuse (i.e., trained word produced for another target item), error type, and communication clarity. All participants showed significant improvement for trained vocabulary. There was no significant increase in misuse of words, with such errors occurring rarely. At a group level, there was an increased tendency toward omission errors for untrained items, and a reduction in semantically related responses. However, this did not impact on clarity scores with no consistent change across participants. In sum, we found no negative impacts following tailored word retraining, providing further evidence of the benefit of these programs for individuals with SD.
\end{abstract}

Keywords: Primary Progressive Aphasia, Semantic Dementia, word retrieval, naming therapy, word relearning, overgeneralisation 


\section{Introduction}

Semantic dementia, the semantic variant of Primary Progressive Aphasia, is a form of frontotemporal dementia in which communication skills are progressively impaired through a loss of conceptual knowledge (Gorno-Tempini et al., 2011; Hodges et al., 1992). An early and striking feature is a marked impairment in the ability to name objects. Neuroanatomically, this is associated with significant atrophy of the temporal lobes, which typically begins focally and asymmetrically in the anterior and ventral portions (more commonly left versus right). Within the first four years, volume of the affected temporal lobe may be reduced by up to $50 \%$ compared to healthy age-matched controls, followed by substantial loss of the other temporal lobe over the next one to two years (Rohrer et al., 2008).

While there are no current medical treatments for this condition, reviews of behavioural interventions - in the form of word retraining programs - have consistently shown that word retrieval for trained items can be improved (Carthery-Goulart et al., 2013; Croot, 2018; Croot et al., 2009; Jokel et al., 2014). While sample sizes are small, given the rarity of the disease, this training effect has been replicated in more than 30 individual cases. The ability for relearning words appears to be supported by the relative health of posterior aspects of the episodic memory network (Ritchey et al., 2015). Post-mortem anatomical studies have shown relative preservation of volume in the body and tail of the hippocampus ( $85 \%$ preserved), and of neurons in other crucial memory relay structures, such as the mammillary bodies and posterior cingulate, throughout the course of the disease (Tan et al., 2014). In addition, the functioning of this network has been supported by behavioural studies which illustrate the ability for new verbal learning for people with semantic dementia (Jefferies et al., 2011).

The utility of retraining words in semantic dementia, however, has been questioned, given the significant impairment sustained within the semantic network. This degradation to semantic knowledge is different in nature to what is experienced by other individuals (e.g., for some people post-stroke) who have difficulty accessing generally intact semantic representations (e.g., Mirman \& Britt, 2014). For people with semantic dementia, conceptual knowledge has been hypothesised to become increasingly compartmentalised, idiosyncratic and rigid (Ikeda et al., 2006; Snowden et al., 1999) as the anterior and medial temporal lobes deteriorate - regions identified as important for both combining information to generalise and when forming concepts (Jefferies, 2013; Patterson et al., 2007).

This bears important implications for the type of training approach selected, with a need to consider the degree of semantic degradation for the items being targeted. While some individuals can relearn words that no longer hold meaning for them, in the absence of additional training to restore semantic knowledge, this arguably achieves little practical benefit (e.g., CR in Snowden \& Neary, 2002, who could successfully name a rolling pin, but added "That's the long thing one. I don't know what it is"). It is therefore important to ensure that when conceptual knowledge is substantially or 
completely degraded that any word retraining is accompanied with additional conceptual training, such as Conceptual Enrichment Therapy (Suárez-González et al., 2018) or other approaches that focus on rebuilding knowledge of semantic features to ensure that retraining is useful.

A further implication of a weakened semantic network relates to the impact this has on a person's ability to generalise. If the ability to generalise is limited, then material learned within the specific training situation may not easily translate to benefit everyday life. In support of this, some studies have shown that certain individuals fail to apply trained labels when different picture stimuli are tested from those used in training (e.g., the right-lateralised case NH in Mayberry et al., 2011).

Importantly, however, most studies have demonstrated at least some ability for people with semantic dementia to apply the trained labels in different language contexts (Cadório et al., 2017). While this occurs to a lesser degree than other forms of primary progressive aphasia, this generalisation can include using trained words in closely related tasks, such as naming alternative pictures of the trained items (Croot et al., 2019; Heredia et al., 2009; Jokel et al., 2016, 2010; and case GE in Mayberry et al., 2011), or applying these words to other expressive or receptive language tasks (Beales et al., 2016; Savage et al., 2014; Suárez-González et al., 2018; Taylor-Rubin et al., 2021). Additional anecdotal reports provide encouraging evidence that trained information can be subsequently used in everyday life (e.g., CS's ability to order muffins following training of this word, as reported in Jokel et al., 2010; see also Croot et al., 2015; Heredia et al., 2009).

While undergeneralisation - where a word fails to be retrieved beyond a certain restricted (trained) context - has been considered in numerous studies, an impaired semantic system may also hinder an individual's communication following retraining due to overgeneralisation (Lambon Ralph \& Patterson, 2008; Mayberry et al., 2011). Overgeneralisations have previously been reported in semantic dementia, when highly familiar or typical names are extended to semantically related objects (e.g., naming a pig as "dog") or category labels are used (e.g., naming pig as "animal") (e.g., Hodges et al., 1995; Lambon Ralph et al., 2001), but have not often been discussed in the context of word retraining. Here, overgeneralisation would occur if newly trained labels, which are successfully applied to the target, might also be misapplied to non-targets, producing a potentially negative effect of training. Such errors could occur if there is a loss of appreciation of the specificity of the label or that component parts of an item may have an alternative, specific name (e.g., that a computer may comprise a keyboard, monitor, mouse and tower and that each individual element is not "a computer" —as reported in Savage et al., 2015b). Similarly, overgeneralisations may arise from lost knowledge regarding the key distinctions that separate neighbouring concepts, causing concepts to converge on the same label, for example, leading to a cat being called a "small dog", or all long thin vegetables being called a "carrot" (Lambon Ralph et al., 2010; Lambon Ralph \& Patterson, 2008; Rogers et al., 2004). Alternatively, in earlier stages of the disease, an individual with semantic dementia might be aware of the error, but knowingly misuse a related word as a way of trying to describe the object in question using lexical items they have available. Consequently, if retraining results in significant 
increases in these kinds of errors, it creates the potential for undesirable increases in misunderstandings, confusion, and frustration in everyday communication.

Despite this potential for overgeneralisation errors, very few word retraining studies to-date have focused on this aspect. Of those that have, results suggest some increase in misapplication of words post-training. Firstly, in a study by Mayberry et al. (2011), which sought to examine both under- and overgeneralisation after training, both individuals with semantic dementia misused trained words more often post - intervention when naming other pictures, particularly when these were visually and semantically related to trained targets ("visual-semantic" foils). Here, approximately 10$20 \%$ of the 30 visual-semantic foils at baseline were mislabelled using a target word. Following 3 weeks of training (that resulted in $>95 \%$ accuracy for trained words), the rate of misuse increased to around $35 \%$ of responses in the milder, right-lateralised case, $\mathrm{NH}$, but up to approximately $55 \%$ of responses to these foils for the left-lateralised and more severe case, GE. Smaller, non-significant increases were observed when foils were distantly semantically related or unrelated.

In another study, Hoffman and colleagues (2015) found that all three of their Study 1 participants misapplied some words in their post-intervention assessment. Rates were relatively low, with less than $5 \%$ of responses in treated or untreated sets showing misapplication of trained words in the right-lateralised participant and up to approximately $15 \%$ of responses in left-lateralised participants. In all instances, errors were in response to naming a visually or semantically related picture. These occurred most often within the treated sets, where trained words were being misapplied to other trained targets. Interpreting the extent to which training encouraged these errors is, however, complicated by a number of factors. Firstly, baseline rates could not be measured in this study (as the words included in the program were deliberately selected on the basis that the person was unable to produce these words prior to training, meaning they could not have been misapplied). Secondly, posttraining performance was collapsed across follow-up sessions which ranged from 1 week to 7 months (thereby intermixing effects of immediate training effects and fading retention). Thus, it is unclear how many instances truly reflected overgeneralisation (i.e., where the word had been correctly applied to the target picture but then also misapplied to other items) rather than simply reflecting degraded knowledge over time, as training effects failed to be maintained.

In Study 2, Hoffman et al. explored the effect of using different depictions of the target items during training on the abilities of the individuals with semantic dementia to generalise their knowledge. When trained on a single exemplar, both individuals mislabelled visual-semantic foils (e.g., a tomato for the target word pepper (red capsicum)) using target words around $20-30 \%$ of the time when tested one week following training. If training used multiple exemplars, mislabelling of visual-semantic foils now increased up to $55 \%$ of the time for one case (MB). While baseline rates were not provided, concerningly the authors further commented that 5 foils previous named correctly at baseline by MB were now incorrectly labelled using one of the trained words. The study concluded 
that while one participant (JW) was largely successful in avoiding overgeneralisation errors, a detrimental effect from training was seen for the other (MB).

This raises important questions regarding the extent and possible impact of overgeneralisation in word retraining. It is important to note, however, that in contrast to many other word retraining studies, the above-mentioned studies did not involve individualised programs, tailored to their participants. Consequently, items may have had low communicative relevance for the participants (e.g., medal), or may not have been well understood, if semantic knowledge for these items was severely eroded. Thus, it is difficult to know whether similar issues of overgeneralisation would be expected in individually tailored item sets where participants are tested on stimuli that are personally relevant and meaningful. In summary, while overgeneralisation has been raised as a potential problem, the evidence to-date is insufficient to make clear interpretations for word retraining programs.

To determine the likelihood and impact of overgeneralisation errors following tailored word retraining, errors need to be examined immediately post-intervention, as compared to pre-intervention rates, and within a greater number of people with semantic dementia. Such an investigation is of clinical importance, as people with semantic dementia and families should be advised of these potential unintended effects of training if this is a likely outcome of engaging in such programs. In addition, if this type of intervention does result in a substantial increase in overgeneralisations, it may be necessary to adjust retraining methods. For example, it may be necessary to include 'compare and contrast' training of within category members, or to train close semantic neighbours at the same time, to minimise such unwanted effects.

Directing attention to these kinds of outcomes of word retraining also raises the question of whether other changes occur when naming trained or untrained items that have not been previously examined and which may be disadvantageous for everyday communication. Such negative consequences could occur if the type of errors originally displayed change in such a way that the overall clarity of attempted communication is reduced. By focusing only on total number of words correct as an outcome to word retraining, these potential issues remain hidden. For example, if a person previously provided semantic descriptions for items they could not name, but following training either provided no information or gave an unrelated word, both responses pre- and posttraining would be counted equally as errors even though one response (i.e., the semantic description) could potentially lead to successful communication. Thus, it is important to not only analyse quantitative differences in naming accuracy pre- and post-training, but to also consider qualitative changes in naming error types. This provides the opportunity to assess the likely communication success of a participant, by analysing the clarity of their responses.

Finally, before exploring such effects, it is important to acknowledge the artificial nature of the testing session, where up to 100 items are shown one at a time and the participant must retrieve the name for each item. Given people with semantic dementia still show some propensity for 
repetition priming (Cumming et al., 2006; Reilly et al., 2005), in the context of a long testing session, the misuse of target words could arise due to increased activation and availability of a word previously named. This may lead to perseverative responding (Moses et al., 2004, 2007) which should be ruled out in order to identify 'true' instances of overgeneralisation.

\subsection{Aims and hypotheses}

The aim of this study was to examine data from a series of participants with semantic dementia $(n=9)$ who had previously taken part in a tailored word retraining program to determine:

1. Is there an increase in misuse (overgeneralisation) of words following word retraining that is not attributable to perseverative or repetitive responding?

2. Do the types of naming errors change from pre- to post-training for items that are not correctly named?

3. Is there a reduction in the clarity of communication when an individual does not retrieve the target word (e.g., because the individual now produces an incorrect word in lieu of providing an accurate description)?

While the rate of misuse overall was predicted to remain low, those participants with severe semantic impairments were anticipated to demonstrate some increase of misuse following training (both in response to trained and untrained items). This was predicted as a consequence of a poorer ability to distinguish among closely related items due to greater semantic degradation. In addition, it was hypothesised that those with greater disease severity may show less ability to inhibit pre-activated responses within a testing session, resulting in an increase in perseverative responding. For those with milder levels of semantic impairment, it was predicted that misuse would decrease in response to training.

Regarding the distribution of error types, no significant changes were predicted in untrained vocabulary, with a reduction in the proportion of "don't know" responses post-training anticipated for the trained list (given participants' increased likelihood of attempting an answer). Finally, no overall reduction in clarity of communication was expected for erroneous responses, although for individuals with severe semantic impairments, it was anticipated that any remaining incorrect responses to trained items may shift from omissions towards target attempts of varying quality (e.g., including coordinate errors and non-word approximations). 


\section{Methods}

\subsection{Participants}

Nine participants who previously took part in a word-relearning study run by FRONTIER (the Frontotemporal Dementia Research Group) in Sydney, Australia, were included in the study. All participants met criteria for the semantic variant of Primary Progressive Aphasia (Gorno-Tempini et al., 2011) based upon a detailed clinical and neuropsychological assessment and structural brain magnetic resonance imaging. Each participant had a history of word finding difficulties, of between 3 and 9 years in duration, and showed marked naming deficits on standard tests when compared with age-matched controls (Table 1). Comprehension and semantic deficits ranged from mild to severe, as did the degree of general cognitive impairment. The typical pattern of anterior and medial temporal lobe atrophy was observed in each case, with greater left than right atrophy in 7 participants, and the reverse pattern in 2 participants (see Figure 1).

\section{Figure 1}

Coronal T1 weighted MRI of the medial temporal lobe for each participant

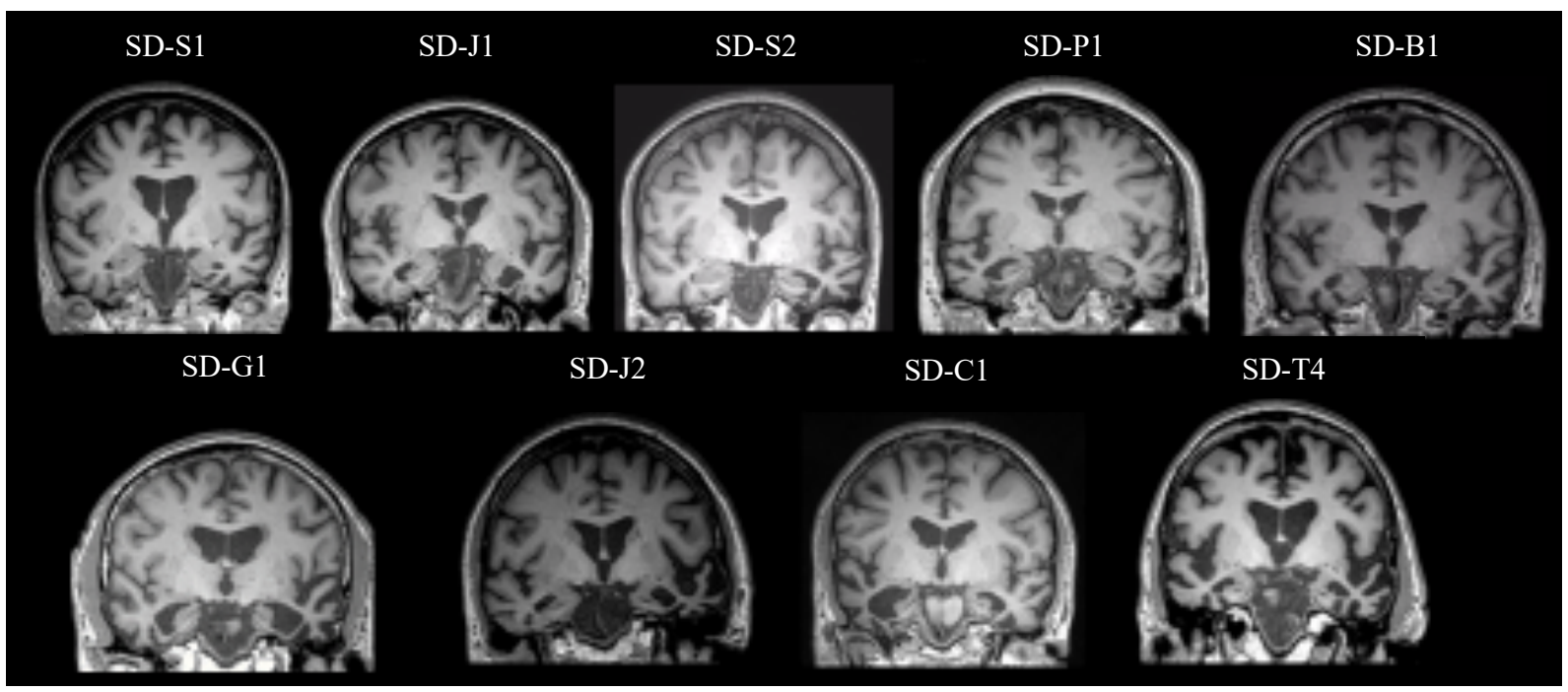

Note. The left hemisphere is shown on the right. Participants SD-P1 and SD-C1 show greater right sided atrophy. 
Table 1

Demographic and clinical profile of study participants

\begin{tabular}{|c|c|c|c|c|c|c|c|c|c|}
\hline & S1 & $\mathbf{J 1}$ & $\mathbf{S 2}$ & P1 & B1 & G1 & $\mathbf{J} 2$ & C1 & T4 \\
\hline Sex & $\mathrm{F}$ & $\mathrm{M}$ & $\mathrm{F}$ & $\mathrm{F}$ & $\mathrm{M}$ & $\mathrm{M}$ & $\mathrm{F}$ & $\mathrm{M}$ & $\mathrm{M}$ \\
\hline Age (years) & 67 & 75 & 60 & 69 & 67 & 70 & 77 & 55 & 70 \\
\hline Education (years) & 14 & 15 & 12 & 11 & 13 & 16 & 15 & 12 & 11 \\
\hline $\begin{array}{l}\text { Disease duration } \\
\text { (years) }\end{array}$ & 6 & 5 & 3 & 6 & 5 & 6 & 9 & 8 & 6 \\
\hline Atrophy pattern & $\mathrm{L}>\mathrm{R}$ & $\mathrm{L}>\mathrm{R}$ & $\mathrm{L}>\mathrm{R}$ & $\mathrm{R}>\mathrm{L}$ & $\mathrm{L}>\mathrm{R}$ & $\mathrm{L}>\mathrm{R}$ & $\mathrm{L}>\mathrm{R}$ & $\mathrm{R}>\mathrm{L}$ & $\mathrm{L}>\mathrm{R}$ \\
\hline $\operatorname{ACE}^{2} \mathbf{R}^{\mathrm{a}}(\mathbf{1 0 0})$ & 80 & 86 & 70 & 79 & 84 & 68 & 56 & 57 & 49 \\
\hline Digit Span $^{\text {b }}$ (Age SS) & 7 & 18 & 11 & 14 & 15 & 10 & 8 & 8 & 7 \\
\hline RCFT Copyc (36) $^{c}$ & 28 & 34 & 31 & 32 & 35 & 36 & 35 & 30 & 34 \\
\hline $\begin{array}{l}\text { RCFT 3-min recall } \\
\text { (36) }\end{array}$ & 19.5 & 23 & 17 & 11.5 & 17 & 22.5 & 25.5 & 9 & 12 \\
\hline $\begin{array}{l}\text { Trail Making Test- } \mathrm{A}^{\mathrm{d}} \\
\text { (s) }\end{array}$ & 39 & 29 & 17 & 31 & 39 & 34 & 35 & 39 & 31 \\
\hline $\begin{array}{l}\text { Trail Making Test-B } \\
\text { (s) }\end{array}$ & 73 & 61 & 67 & 58 & 41 & 80 & 111 & 78 & 88 \\
\hline SYDBAT Total (120) & 98 & 97 & 85 & 85 & 78 & 71 & 68 & 62 & 46 \\
\hline Naming $^{\mathrm{e}}(30)$ & $16^{\mathrm{f}}$ & $16^{\mathrm{f}}$ & $5^{f}$ & $14^{\mathrm{f}}$ & $10^{\mathrm{f}}$ & $8^{f}$ & $8^{f}$ & $4^{\mathrm{f}}$ & $2^{f}$ \\
\hline $\operatorname{Repetition}^{\mathrm{e}}(\mathbf{3 0})$ & 30 & 29 & 30 & 29 & 30 & 29 & $28^{f}$ & 29 & $25^{\mathrm{f}}$ \\
\hline Comprehension $^{\mathrm{e}}(\mathbf{3 0})$ & 26 & 27 & 28 & $21^{\mathrm{f}}$ & $19^{\mathrm{f}}$ & $17^{\mathrm{f}}$ & $17^{\mathrm{f}}$ & $14^{\mathrm{f}}$ & $12^{\mathrm{f}}$ \\
\hline Semantic $^{\mathrm{e}}(\mathbf{3 0})$ & 26 & 25 & $22^{f}$ & $21^{\mathrm{f}}$ & $19^{\mathrm{f}}$ & $17^{\mathrm{f}}$ & $15^{f}$ & $15^{\mathrm{f}}$ & $7^{\mathrm{f}}$ \\
\hline
\end{tabular}

Note. Participant labels have been retained from Savage et al. (2015a), with the addition of S2 (previously unpublished); $\mathrm{L}>\mathrm{R}=$ left greater than right temporal lobe atrophy; $\mathrm{R}>\mathrm{L}=$ right greater than left temporal lobe atrophy; SS = scaled score; $\mathrm{s}=$ seconds taken to complete; numbers in parentheses refer to maximum score for that assessment.

a Addenbrooke's Cognitive Examination-Revised (Mioshi et al., 2006), where healthy control cut-off is 88 and dementia cut-off score is 82 .

${ }^{\mathrm{b}}$ Total score on Digit Span subtest of the Wechsler Adult Intelligence Scale (Wechsler, 1997).

${ }^{\mathrm{c}}$ Rey Complex Figure Test (RCFT; Meyers \& Meyers, 1995).

d Trail-Making Test (Strauss et al., 2006).

${ }^{\mathrm{e}}$ Sydney Language Battery; healthy control means: naming $=26.6$; repetition $=29.9$; comprehension $=29.1$; semantic $=27.7$.

${ }^{\mathrm{f}}$ Performance more than 2 standard deviations below the mean of neurotypical controls. 
Each participant completed an individualised word retraining program, where picture naming accuracy was the primary outcome measure. Full details regarding the training program and postintervention naming accuracy have been reported previously for eight of the participants (Savage et al., 2014, 2015a). An additional participant (S2 - previously unpublished) was included in this study, having subsequently completed the program. In all cases, significant improvements in naming accuracy were found when comparing baseline to immediate post-intervention performance for trained items (all $p<.005$, see also Table 3). To be eligible for analysis in the current study, verbal naming performance data for trained (List 1) and untrained (Lists 2 and 3) words were required both at baseline, and 4 weeks later, after completing training on their first list of 30-35 words (approximately 20 training sessions). Three previously reported participants (J3 and J5 from Savage et al., 2014 and C2 from Savage et al., 2015a) were excluded from this analysis, due to either smaller word lists or problems with the sound recordings of the 4-week assessment, limiting the ability to conduct detailed error analyses.

The data were collected under ethical approval from the Human Research Ethics Committees of South Eastern Sydney Illawarra Area Health Service and the University of New South Wales. All participants gave written informed consent either themselves or through their next of kin.

\subsection{Design}

The original study (Savage et al., 2014) used a single subject experimental design, in which the naming behaviour on three matched word lists (Lists 1-3) was monitored over a baseline and intervention phase. First, naming performance was tested over a 4-week period to establish baseline performance. Stability in naming accuracy was confirmed for each participant prior to commencing training using Cohen's kappa to examine responses across consecutive sessions (see van Scherpenberg et al., 2019, for analyses on these baseline data).

After the baseline period, participants practiced their individual List 1 for 4 weeks, followed by training of List 2 for 4 weeks, while List 3 remained untrained. At the end of each week, participants were assessed on all three word lists. For the purposes of this study, data were only examined from the final baseline assessment and the immediate post-test following training of List 1 (Lists 2 and 3 were both untrained at this point), in order to investigate the impact of learning, without any effects of maintenance.

Stimuli and word lists were individualised for each participant, with initial baseline tests confirming that the images were clear to the participants and that participants could recognise and provide some semantic information for all items. Each participant was tested on approximately 100 items, divided into 3-word lists matched for word frequency, semantic category, and baseline naming performance (see Savage et al., 2014, 2015a). Lists were constructed to include 4-6 semantic categories, such that each list contained multiple items from a given category. In addition, where possible, lists were constructed so that for a given trained word, a close coordinate would appear in 
the untrained lists (e.g., if "air conditioner" was trained, then "heater" was untrained). See Appendix A for an example of the items included for participant B1.

Training involved pairing each target word with a single image of the object, often using photographs taken at the participant's home. During each training session, participants would first see the photograph of the object on the computer screen, and then click the mouse or press a button on the keyboard to both see the written label and hear an audio recording of the object name. Participants were encouraged to repeat the word out aloud, before clicking to move on. After seeing all items within the training list the first time, the procedure would be repeated a second time, using a different randomised order of presentation. Following both rounds of practice, participants would complete a short naming test of the items they had just practised. Participants would provide their responses both verbally and by typing their answer. Participants completed these sessions 5 days per week.

On the sixth day of the week, naming tests were administered via computer and required participants to name each object shown on the screen within 10 seconds of its appearance. Item order was randomised. An audio recording of the response was generated, with responses later transcribed. Participants were then asked to type the response they had given (with no time limit imposed).

The current analysis focused on the transcribed audio responses. For any item where the recording failed or was unclear (e.g., the sound file ended halfway through a word), the item was excluded from analysis. A table summarising the number of items retained in each list for each participant can be found in Appendix A.

\subsection{Misuse and repetition}

\subsubsection{Misuse}

Responses were coded to identify instances of misuse of words, both at baseline and postintervention. This was defined as the use of a target word from the (to be) trained List 1 in reference to another item from either List 1 or untrained Lists 2 and 3. A significant increase in the rate of instances of misuse from baseline to post-intervention was considered evidence for a negative effect of training (with individual analyses being conducted using McNemar's Test for related samples and a group analysis being conducted using a Wilcoxon signed-rank test). This was examined both for misuse of List 1 words for other items in that list, as well as for misuse of List 1 words for untrained List 2 or 3 items (using a Bonferroni corrected significance threshold of $p<.05 / 2=.025$ ).

\subsubsection{Repetitions}

As a separate but related measure, repetitions of any target words were identified for each individual within the baseline and post-intervention assessments. A response was considered repetitive if any (treated or untreated) target word was produced more than once in a naming session. This could be in response to more than one non-target picture (regardless of whether the target picture was correctly named), or in response to the target picture and at least one other subsequent picture. 
This analysis was used to check for perseverative patterns of responding within a testing session, in order to discriminate this possible cause of misuse from overgeneralisation of a trained concept. Again, a significantly increased rate of repetition from baseline to post-intervention was considered evidence of a potentially negative effect of training (with individual analyses conducted using McNemar's Test of related samples and group analysis conducted using Wilcoxon signed-rank test).

\subsection{Error profiles}

Each response from the final baseline and from the post-intervention assessment (4 weeks later) was assigned an error type based on a modified version of the coding system devised by Best et al. (2005). First, responses were divided into those containing target attempts (i.e., where an object name is produced), and those without (i.e., responses involving only descriptions - e.g., "a device for measuring vegetables and things like that", associated episodic details - e.g., "I had two of them this morning", or statements indicating that the word was unknown-e.g., "some sort of insect, but I don't know which one") (see Appendix B for details). Comments prior to the target attempt or incomplete utterances were disregarded (e.g., in "oh, those little things there.... What are they called? Oh yes, bees", only "bees" was coded as a target attempt; "lem... Er.. They're grapes", only "grapes" was coded as a target attempt). If participants verbalised their decision making, the response coded was the first following the verbalised decision (e.g. "tissues or paper towels, I'll say paper towels", "paper towels" was coded as a target attempt), but where subsequent self-corrections followed a target attempt these were disregarded (e.g. "kettle.. No! This is a coffee percolator", "kettle" was coded as a target attempt).

All identified responses that were target and non-target attempts were then classified into the categories summarised in Table 2. To ensure reliability of target attempt identification and error coding, responses were double-coded. For the response categories of correct, semantic errors, nonsemantic descriptions, omissions, and partially correct responses, independent coding resulted in 98.44\% agreement across two raters. For the remaining responses (semantic descriptions, other errors), given the greater subjectivity, coding was compared among three raters, with any disagreements discussed and recoded by consensus. Full guidelines for identification of target attempts and naming error coding are provided in Appendix B.

Based upon this coding, pre- and post-intervention error profiles were constructed for each participant. The change in error profiles across the group was analysed using the Cochran-MantelHaenszel test (Agresti, 2002), a chi-squared test for count data using R Studio (version 1.3.1093; RStudio Team, 2020) and the base R package stats (version 4.0.3). The data were grouped by participants, so that the chi-squared test ran on a 6 (error categories) x 2 (time points) contingency table to determine if the distribution of errors observed at baseline for untrained words remained unchanged at post-intervention. A prerequisite of this test is that there are no significant three-way 
interactions in the data (e.g., the error category cannot depend on the testing time point and on the participant). This was confirmed with the Woolf test from the R package ved (Meyer et al., 2017).

Table 2

Response coding

\begin{tabular}{|c|c|c|}
\hline Category & Subcategories & Examples \\
\hline \multirow{3}{*}{ Correct } & Target response & "knife" for picture knife \\
\hline & Acceptable alternative & "TV" for picture television \\
\hline & Plurals & "apples" for picture apple \\
\hline $\begin{array}{l}\text { Partially correct } \\
\text { response }\end{array}$ & & "cutting pad" for picture cutting board \\
\hline \multirow{3}{*}{ Semantic errors } & Coordinate & "sauce" for picture jam \\
\hline & Superordinate & "vegetable" for picture potato \\
\hline & Associate & "salt" for picture peanuts \\
\hline \multirow{2}{*}{$\begin{array}{l}\text { Semantic } \\
\text { descriptions }\end{array}$} & $\begin{array}{l}\text { Semantically based } \\
\text { descriptions }\end{array}$ & $\begin{array}{l}\text { "a device for measuring vegetables and things like } \\
\text { that" for picture kitchen scales }\end{array}$ \\
\hline & $\begin{array}{l}\text { Superordinate } \\
\text { description }\end{array}$ & $\begin{array}{l}\text { "some sort of insect, but I don't know which one" } \\
\text { for picture fly }\end{array}$ \\
\hline \multirow{2}{*}{$\begin{array}{l}\text { Non-semantic } \\
\text { descriptions }\end{array}$} & Episodic memory & "I had two of them this morning" for picture eggs \\
\hline & $\begin{array}{l}\text { Orthographic } \\
\text { description }\end{array}$ & "oh it starts with m" for picture mandarin \\
\hline \multirow{6}{*}{ Other errors } & Unrelated real words & "chickens" for picture strawberry \\
\hline & Incorrect superordinate & "tool" for picture placemats \\
\hline & Other descriptions & "little guys" for picture mosquito \\
\hline & $\begin{array}{l}\text { Nonword } \\
\text { (phonologically related } \\
\text { and unrelated) }\end{array}$ & "scaptula" for picture spatula \\
\hline & $\begin{array}{l}\text { Morphological } \\
\text { neologism }\end{array}$ & "vacuumer" for picture vacuum cleaner \\
\hline & Visual error & "snake" for picture belt \\
\hline Omissions & & "I don't know" or no response within 10 seconds \\
\hline
\end{tabular}

\subsection{Communication clarity}

Finally, each response at baseline and post-intervention was scored for clarity using a scale of -1 through to +1 . This involved assigning a numeric value $(-1,-0.5,0,0.5$ or 1$)$ to each response based on the naming error type that had previously been coded (where inter-rater reliability of coding was 
high at $98.44 \%$ ). On this scale, -1 represents a response which is unrelated to the target and consequently would be misleading to a communication partner, -0.5 is an associate or coordinate error which would be (less) misleading to a communication partner, 0 indicates an omission or nonspecific, vague response but without incorrect information, 0.5 is a related response that provides correct and non-conflicting information but does not contain the correct label, and 1 a correct response. Full scoring guidelines for this clarity of response measure are provided in Appendix B. To evaluate any significant change in communication clarity scores of items from pre- to postintervention, Wilcoxon sign-ranked tests were performed for each individual and then for all participants as a group. Trained and untrained words were examined separately, given the prediction that clarity of trained words should improve, but clarity of untrained words should remain unchanged. A Bonferroni correction was applied to account for multiple testing (i.e., alpha value $p<.05 / 2=$ $.025)$.

\section{Results}

Naming accuracy for trained words significantly improved from baseline to immediate postintervention at both the individual (McNemar's Test, all $p<.005$; see Table 3), and at the group level of analysis (Wilcoxon signed-rank test, $p=.008$ ). Accuracy for untrained words remained stable for the group (Wilcoxon signed-rank test, $p=.401$ ) and for each participant (McNemar's Test, all $p>$ $.05)$, with the exception of $\mathrm{S} 2$, who significantly improved after independently training herself on some of the untrained words, by asking friends and family members for the correct responses.

\subsection{Misuse and repetition of words: Is there an increase in misuse (overgeneralisation) of words} following word retraining that is not attributable to repetitive responding?

Analyses for both misuse and repetition of treated words revealed no significant increase from baseline to post-intervention. This was found at both the individual and group-level, and applied to both responses made to other trained items and to response made within the untrained set (see Table 3; Appendix $\mathrm{C}$ for a full summary of all occurrences).

Misuse of trained items to name another item in the trained set was rare. Only four instances (observed across J1, C1, and T4) occurred at baseline, dropping to two instances (in G1 and C1) at post-test. Group analyses indicated no significant change (Wilcoxon signed-rank test, $p=.285$ ). For the untrained set, seven of the nine participants incorrectly used at least one (to be) trained target word at baseline to name another item, however, such errors remained relatively sparse over time (1-6\% of responses per individual). There was no significant increase for any individual (McNemar's Test, all $p$ $>$.06), or evidence of a group level increase in misusing trained labels for untrained words at postintervention (Wilcoxon signed-rank test, $p=.116$ ).

Contrary to expectation, the rate of misuse did not systematically vary according to the degree of semantic impairment, with most participants showing such errors around $1-3 \%$ of the time 
(participants in all tables are ordered from least to most severely semantically impaired as assessed by the Sydney Language Battery). One participant, J2, was observed never to incorrectly apply a target word to another item. At post-intervention, five of the participants either demonstrated the same frequency (S2, B1, J2) or showed a non-significant reduction of these errors (P1, C1). Four participants (S1, J1, G1, T4) showed a non-significant increase in misuse of a trained item when naming untrained targets. Interestingly, T4, the most severely impaired participant, showed the biggest increase following training, however, only in the untrained set (5 additional overgeneralisations) and this was also non-significant ( $p=.063$; see Table 3 ).

Further examination of the context of misuse of trained labels revealed that in 34 of the 39 instances (across all participants, time points and word lists), the misused word had also been correctly applied to the target item within the same testing session, and was semantically related to the alternative item. This supported an interpretation of overgeneralisation of target words. In a small number of cases, target words were misused for semantically unrelated items (e.g., T4: "mandarin" for microwave; see Appendix C). This, however, only happened in the context of severe semantic impairment, and was often acknowledged as an error (e.g., for the item strawberries, T4's response was "not chickens").

Similar to the results for misuse, the rate of repetitive responding within a testing session was also relatively low (up to $5 \%$ of responses for an individual) and tended to remain stable or show slight and non-significant reductions after training (except for T4, who showed slight, but nonsignificant, increase after training; McNemar's Test, all $p>.375$; Table 3). Again, this was confirmed at the group level, with no evidence for a significant change in the rate of repetitions from pre- to post-intervention (Wilcoxon sign-ranked test, $p=.176$ ). Thus, relearning target words did not seem to encourage perseverative retrieval even in those with more severe semantic impairment. 
Table 3

Pre- and post-intervention rates of accuracy, misuse and perseveration by individual at baseline (BL) and post-intervention (number correct or number of misuses / total number of stimuli)

\begin{tabular}{|c|c|c|c|c|c|c|c|c|c|c|c|c|c|c|c|}
\hline \multirow[b]{2}{*}{ Case } & \multicolumn{3}{|c|}{$\begin{array}{c}\text { Accuracy: Trained words } \\
\text { naming accuracy }\end{array}$} & \multicolumn{3}{|c|}{$\begin{array}{c}\text { Accuracy: Untrained words } \\
\text { naming accuracy }\end{array}$} & \multicolumn{3}{|c|}{$\begin{array}{l}\text { Misuse: Trained targets } \\
\text { to name other trained } \\
\text { words }\end{array}$} & \multicolumn{3}{|c|}{$\begin{array}{l}\text { Misuse: Trained targets to } \\
\text { name untrained words }\end{array}$} & \multicolumn{3}{|c|}{$\begin{array}{l}\text { Perseveration: Repetition } \\
\text { errors per testing session }\end{array}$} \\
\hline & $\mathrm{BL}$ & Post & $\begin{array}{l}\text { Pre-post } \\
\text { change } \\
(\text { exact } p)\end{array}$ & $\mathrm{BL}$ & Post & $\begin{array}{l}\text { Pre-post } \\
\text { change } \\
(\text { exact } p)\end{array}$ & $\mathrm{BL}$ & Post & $\begin{array}{l}\text { Pre-post } \\
\text { change } \\
(\text { exact } p)\end{array}$ & $\mathrm{BL}$ & Post & $\begin{array}{l}\text { Pre-post } \\
\text { change } \\
(\text { exact } p)\end{array}$ & $\mathrm{BL}$ & Post & $\begin{array}{l}\text { Pre-post } \\
\text { change } \\
(\text { exact } p)\end{array}$ \\
\hline $\mathrm{S} 1$ & $15 / 32$ & $31 / 32$ & $<.001$ & $36 / 64$ & $33 / 64$ & .607 & $0 / 32$ & $0 / 32$ & NA & $2 / 64$ & $3 / 64$ & 1.0 & $5 / 96$ & $2 / 96$ & .250 \\
\hline $\mathrm{J} 1$ & 13 / 30 & $30 / 30$ & $<.001$ & $28 / 57$ & $26 / 57$ & .625 & $2 / 30$ & $0 / 30$ & .50 & $1 / 57$ & $3 / 57$ & .50 & $2 / 87$ & $1 / 87$ & 1.0 \\
\hline $\mathrm{S} 2$ & $11 / 31$ & 29 / 31 & $<.001$ & $20 / 66$ & $31 / 66$ & .013 & $0 / 31$ & $0 / 31$ & NA & $1 / 66$ & $1 / 66$ & 1.0 & $1 / 97$ & $0 / 97$ & 1.0 \\
\hline $\mathrm{P} 1$ & $10 / 32$ & $31 / 32$ & $<.001$ & $26 / 65$ & $26 / 65$ & 1.0 & $0 / 32$ & $0 / 32$ & NA & $4 / 65$ & $3 / 65$ & 1.0 & $2 / 97$ & $1 / 97$ & 1.0 \\
\hline B1 & $14 / 30$ & $30 / 30$ & $<.001$ & $28 / 65$ & $29 / 65$ & 1.0 & $0 / 30$ & $0 / 30$ & NA & $1 / 65$ & $1 / 65$ & 1.0 & $3 / 95$ & $1 / 95$ & .500 \\
\hline G1 & 17 / 31 & $28 / 31$ & .003 & $30 / 62$ & 33 / 62 & .375 & $0 / 31$ & $1 / 31$ & 1.0 & $1 / 62$ & $2 / 62$ & 1.0 & $2 / 93$ & $2 / 93$ & 1.0 \\
\hline $\mathrm{J} 2$ & $14 / 25$ & $25 / 25$ & .001 & $19 / 39^{a}$ & $20 / 39^{a}$ & 1.0 & $0 / 25$ & $0 / 25$ & NA & $0 / 39$ & $0 / 39$ & NA & $0 / 64$ & $0 / 64$ & NA \\
\hline $\mathrm{C} 1$ & $16 / 38$ & 34 / 38 & $<.001$ & $32 / 72$ & $41 / 72$ & .064 & $1 / 38$ & $1 / 38$ & 1.0 & $3 / 72$ & $2 / 72$ & 1.0 & $4 / 110$ & $1 / 110$ & .375 \\
\hline $\mathrm{T} 4$ & $8 / 29$ & $27 / 29$ & $<.001$ & $22 / 71$ & 19 / 71 & .375 & $1 / 29$ & $0 / 29$ & 1.0 & $0 / 71$ & $5 / 71$ & .063 & $2 / 100$ & $5 / 100$ & .453 \\
\hline ALL & $118 / 278$ & $265 / 278$ & .008 & $241 / 561$ & $258 / 561$ & .401 & $4 / 278^{b}$ & $2 / 278$ & .285 & $13 / 561^{b}$ & $20 / 561$ & .116 & 21/839 & $13 / 839$ & .176 \\
\hline
\end{tabular}

${ }^{a}$ Although J2's word lists comprised 32 items each, given problems with sound recording, only those items with clear and complete responses were included in the analysis, reducing the total number.

${ }^{b}$ Note that the proportions of misuse at baseline are equivalent, with no significant difference in misuse of (to-be) trained targets when naming other (to-be) trained words versus when naming untrained words prior to intervention $\left(\chi^{2}(1)=.35, p=.555\right.$, Pearson's Chi-square test with Yates' continuity correction). 


\subsection{Analysis of error profiles: Does the type of naming errors change from pre-to post-training for} items that are not correctly named?

Target attempts (i.e., a name) versus non-target attempts (i.e., a description or omission) were identified in 66\% of responses at baseline (List 1 - trained: 64\%; Lists 2 and 3 - untrained: 68\%), and $83 \%$ at post-intervention (List 1 - trained: $98 \%$; Lists 2 and 3 - untrained: 67\%). While the proportion of target attempts at baseline-varied among participants, from $38 \%$ of responses (S2) to $86 \%(\mathrm{G} 1)$ of responses, individual proportions remained largely stable across time for untrained items (McNemar's Test $p>.21$ in all but 2 cases). As a result, there was no significant change in the level of target attempts for untrained items in the group overall (Wilcoxon sign-ranked test, $p=.859$ ). Of the two individual exceptions, $\mathrm{J} 1$, produced fewer target attempts at the post-intervention assessment, despite maintaining a similar level of naming accuracy ( $70 \%$ down to $58 \%$ of responses to untrained items; McNemar's Test $p=.039$ ). By contrast, S2, generated a higher proportion of target attempts ( $38 \%$ up to $52 \%$ target responses for untrained items; McNemar's Test $p=0.49$ ), after instigating her own practice of certain items from the untrained list.

Frequency of the major error types for each individual are shown in Figure 2, with group results summarised in Table 4. For most individuals, naming errors were spread across 4 to 5 different types at both baseline and (for untrained items) at post-intervention. Most common, however, taken across both time-points and across trained and untrained items, were omissions ( $19.5 \%$ of all responses). These comprised the single largest error category for most participants (at baseline: dominant in 5/9 individuals, encompassing $6.3-61.9 \%$ of responses; at post-intervention: dominant in $7 / 9$ individuals, comprising $1.2-35.1 \%$ of responses). The second most dominant error type was semantic errors ( $9 \%$ of all responses; at baseline: dominant in 4/9 individuals and second most dominant error type in the remaining 5 individuals, reflecting $4.7-21.7 \%$ of responses; post-test: dominant in 2/9 individuals and second most dominant error type in 5/9 individuals, observed in 1.6$14.4 \%$ of responses). Within these semantic errors, coordinate errors were the most common subtype.

Although it was not possible to conduct statistical analysis on individual error patterns across time, the following observations could be made based on visual inspection of data. For trained words (Figure 2a), the range of errors was reduced at post-intervention. In line with our predictions, most participants were now either error-free (J1, B1, J2), or demonstrated only one error type (S1: partially correct response, S2: omissions, P1: coordinate errors). For the remaining 3 participants, up to three error types were observed per person (G1: other errors, semantic - coordinate errors; T4: other errors, partially correct response; $\mathrm{C} 1$ : semantic - coordinate errors, semantic description, partially correct response). When examining untrained words (Figure $2 b$ ), some participants showed a fairly stable pattern of error responses across time (e.g., P1, G1, J2). While the range of error categories often remained similar, for some participants the relative distribution of errors within these categories showed some change (e.g., C1 appeared to show fewer semantic description errors, at the second time point, but greater omissions). 


\section{Figure 2}

Individual error profiles at baseline and post-intervention for a) trained items and b) untrained item

a) Trained items

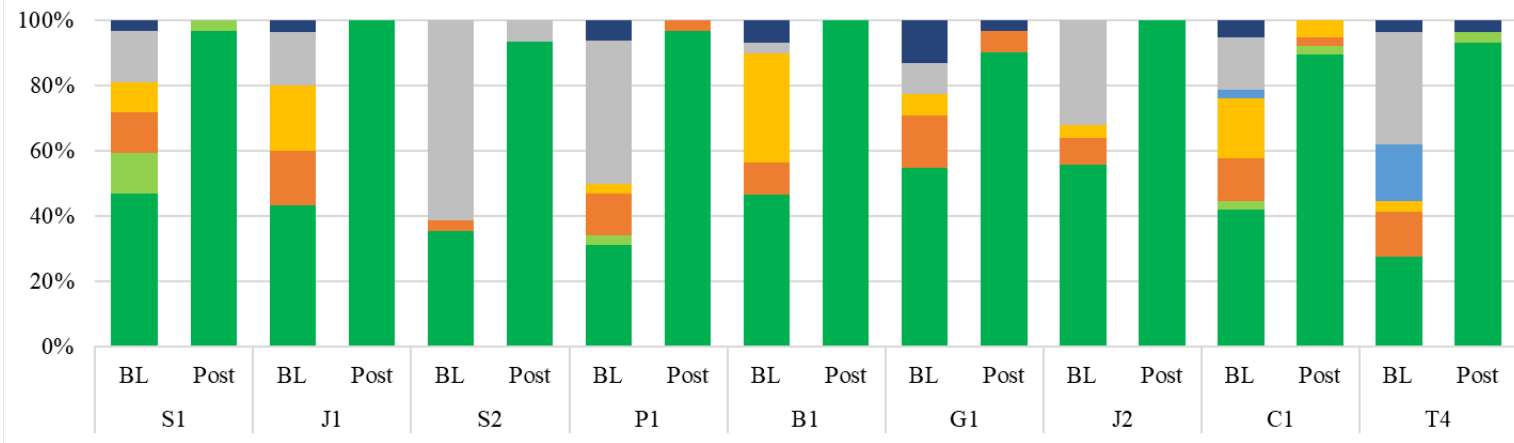

b) Untrained items

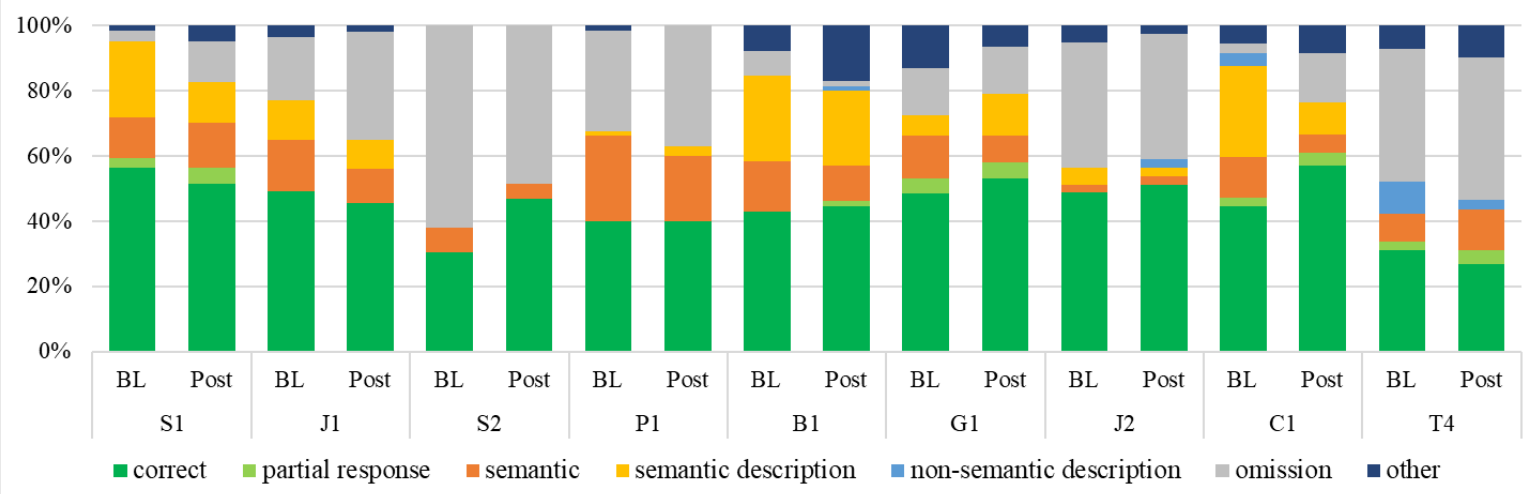

At the group level (Table 4), only 13 errors remained at post-intervention for trained words. Consequently, statistical analyses regarding changes in error category for these words were not possible. Descriptively, a reduction in omission errors was observed (down by $29 \%$ ), with increases in partially correct responses (up by 11\%), semantic errors (up by 10\%), and other errors (up by 7\%).

For untrained words, in contrast to our predictions, group-level analyses revealed an overall change in the pattern of error responses, with a significant association found between the time point and error category (Cochran-Mantel-Haenszel test for repeated tests of independence: $\chi^{2} \mathrm{MH}(5)=12.245, p=$ .032 ; Woolf test: $\chi^{2}(8)=3.734, p=.880$ confirming the appropriateness of the Cochran-MantelHaenszel test). Naming errors with a semantic component (i.e., semantic descriptions and semantic errors, including coordinates, superordinates, associates) and omissions continued to account for the bulk of errors across time ( $86 \%$ at baseline; $84 \%$ at post-intervention). Follow-up analyses found a significant increase in omissions post-intervention, when compared with all other error types (Cochran-Mantel-Haenszel test, omissions vs all other error types on untrained items across time: $\chi^{2} \mathrm{MH}(1)=5.634, p=.018$; Woolf test: $\left.\chi^{2}(8)=13.125, p=.108\right)$ and a significant decrease in naming errors with a semantic component (Cochran-Mantel-Haenszel test, semantic component errors vs all other error types on untrained items across time: $\chi^{2} \mathrm{MH}(1)=7.554, p=.006$; Woolf test: $\chi^{2}(8)$ $=11.622, p=.169)$. When looking at the two types of semantic errors separately, however, decreases 
for each component were non-significant (Cochran-Mantel-Haenszel test comparing, for untrained items across time points: i) the pattern of semantic descriptions vs all other error types: $\chi^{2} \mathrm{MH}(1)=$ $3.456, p=.063$; Woolf test: $\chi^{2}(8)=9.475, p=.304$; ii) the pattern of semantic errors vs all other error types: $\chi^{2} \mathrm{MH}(1)=1.754, p=.185$; Woolf test: $\left.\chi^{2}(8)=2.732, p=.950\right)$.

\section{Table 4}

Percentage of errors of each type for trained and untrained items at baseline and post-intervention combined across participants $(n=9)$

\begin{tabular}{|c|c|c|c|c|}
\hline \multirow[b]{2}{*}{ Error type } & \multicolumn{2}{|c|}{ Trained items } & \multicolumn{2}{|c|}{ Untrained items } \\
\hline & $\begin{array}{l}\text { Baseline } \\
(n=160)\end{array}$ & $\begin{array}{c}\text { Post-intervention } \\
\quad(n=13)\end{array}$ & $\begin{array}{l}\text { Baseline } \\
(n=320)\end{array}$ & $\begin{array}{l}\text { Post-intervention } \\
\quad(n=303)\end{array}$ \\
\hline \% partially correct & 4 & 23 & 3 & 4 \\
\hline$\%$ semantic error (total) & 21 & 31 & 23 & 19 \\
\hline Coordinate & 14 & 31 & 16 & 15 \\
\hline Superordinate & 6 & 0 & 6 & 4 \\
\hline Associative & 1 & 0 & 1 & 0 \\
\hline$\%$ semantic description & 19 & 15 & 21 & 15 \\
\hline $\begin{array}{r}\% \text { non-semantic } \\
\text { description }\end{array}$ & 4 & 0 & 3 & 1 \\
\hline$\%$ omissions & 44 & 15 & 42 & 50 \\
\hline$\%$ other & 8 & 15 & 9 & 11 \\
\hline
\end{tabular}

3.3 Clarity of response: Is there a reduction in the clarity of communication when an individual produces an error?

Comparison of individual clarity scores from baseline to post-intervention revealed significant improvements for trained words, in accordance with the increase in correct responses: This was observed for all participants over the course of the intervention, with the exception of G1, whose improvement was marginally significant, following correction for multiple comparisons $(p=.029$; Table 5). Consequently, the improvement in clarity of responses to trained items was also observed post-treatment at the group level (Wilcoxon sign-ranked test, $p=.008$ ).

Little change, however, was seen for untrained words (Table 5), as predicted. While a marginally significant decrease for clarity in untrained words was observed for J1 $(p=.029)$, due to higher omission errors, this contrasted with G1's improved clarity $(p=.013)$. G1 made fewer coordinate errors or responses containing incorrect information at post-intervention, in favour of partially correct or correct responses. S2 also showed increased clarity $(p=.010)$ with fewer omissions and increased correct responses, however, as noted earlier, she had spontaneously practiced 
some of the untreated words. Overall, for the group, there was no evidence for reduced clarity in untrained words (Wilcoxon sign-ranked test, $p=.515$ ).

\section{Table 5}

Wilcoxon tests for each participant and for all participants as a group

\begin{tabular}{lcccccccc}
\hline & \multicolumn{3}{c}{ Trained items } & & \multicolumn{3}{c}{ Untrained items } \\
\cline { 2 - 3 } \multicolumn{1}{c}{ Case } & BL & Post & (Wilcoxon), $\boldsymbol{p}$ & & BL & Post & (Wilcoxon), $\boldsymbol{p}$ \\
\hline S1 & 0.578 & 0.984 & $<.001$ & & 0.680 & 0.539 & .071 \\
J1 & 0.483 & 1.000 & $<.001$ & & 0.544 & 0.430 & .029 \\
S2 & 0.339 & 0.935 & $<.001$ & & 0.295 & 0.462 & .010 \\
P1 & 0.297 & 0.953 & $<.001$ & & 0.308 & 0.346 & .272 \\
B1 & 0.583 & 1.000 & $<.001$ & & 0.469 & 0.508 & .475 \\
G1 & 0.468 & 0.839 & .029 & & 0.371 & 0.548 & .013 \\
J2 & 0.540 & 1.000 & .002 & & 0.474 & 0.526 & .595 \\
C1 & 0.461 & 0.921 & $<.001$ & & 0.597 & 0.611 & .839 \\
T4 & 0.276 & 0.948 & $<.001$ & & 0.197 & 0.148 & .449 \\
ALL & 0.446 & 0.951 & .008 & & 0.433 & 0.453 & .515 \\
\hline
\end{tabular}

Note. BL denotes baseline assessment.

Alpha level for Bonferroni corrected $p$-value: $p<.025$.

\section{Discussion}

Word retraining studies over time have highlighted the improved ability of participants with semantic dementia to name pictures of trained items post-intervention. What has remained unclear has been whether such training has significant adverse effects for untrained vocabulary. From a detailed analysis of nine participants undertaking a tailored word retraining program, encouragingly we found that improved word retrieval for trained targets did not lead to a significant misuse of vocabulary, or have a detrimental effect on the clarity of communication. While at a group level, participants' error patterns changed for untrained items at post-intervention, with more omissions and less semantically related errors made (i.e., semantic errors and semantic descriptions), importantly, this did not reduce clarity of communication. Of note, these results were observed across participants whose severity of semantic impairment ranged from mild to severe. This was in the context of personalised training which involved single exemplars of items, for which some conceptual knowledge remained. 


\subsection{Misuse and repetition of words}

Consistent with observations made from previous studies, participants in the current study did occasionally use target words erroneously when naming other pictures. As in Hoffman et al. (2015) and Mayberry et al. (2011), this misuse of the trained word was typically in response to another target word that was semantically related (see Appendix C). Although other studies have particularly described such post-training errors as occurring within the therapy list (e.g. CUB in Heredia et al. (2009), CR in Snowden and Neary (2002); but also MB and JW in Hoffman et al., 2015), misuse for trained words within the current trained sets was very rare. Such instances occurred less than $1 \%$ of the time overall (with individual rates ranging from $0 \%$ to $3 \%$ of naming responses to items from the trained set post-intervention). Indeed, only two individuals made this kind of error: G1 (calling a steak a "silver beet" but immediately self-correcting) and $\mathrm{C} 1$ (who used an unrelated word, calling the picture rubber band a "button"). A slightly higher rate of misuse was seen within the untrained words ( $4 \%$ of responses overall; with the highest individual rate of 7\%), but at the lower end of what has previously been reported (e.g., in Study 1 of Hoffman et al, 2015).

One factor which can influence the likelihood of overgeneralisation is the semantic neighbourhood density of categories tested. For some people with aphasia, coordinate errors become more likely when the item tested belongs to a category that has closely related members (e.g., animals, fruits) rather than a category that does not (e.g., artifacts) (Hameau et al., 2019, 2020). This is unlikely to explain the current difference in results, however, as the studies by Hoffman et al. (2015) and Mayberry et al. (2011) included items from similar semantic categories to the current study (e.g., animals, fruit and vegetables, kitchen utensils, household items, clothing).

Two important differences among the studies may offer a better explanation. Firstly, the testing materials in the Mayberry study involved carefully selected visual-semantic foils, deliberately designed to draw out such overgeneralisation errors. While our word lists also included other items from each target item's semantic category, these were not deliberately chosen to provide high semantic and visual similarity for every trained item. Thus the opportunity for error may have been higher in the Mayberry study (for evidence that semantic similarity influences naming in individuals with stroke aphasia see Lampe et al. (2021), and for influences in unimpaired participants see, e.g., Lampe et al., 2021; Rose et al., 2019; Rose \& Rahman, 2017).

In addition, the participants' familiarity with the specific images they were asked to name may have influenced the likelihood of overgeneralisation errors. As stimuli were not personalised in the Mayberry or Hoffman studies, this may have encouraged more guessing and incorrect use of known, related words in these studies. By contrast, using stimuli that incorporated photographs of the participants' own objects from their home, may have lessened overgeneralisation as participants may have recognised and successfully discriminated among these images. As these stimuli are arguably more like what would be encountered by the participants in real-life communications at home, we 
speculate that this lower rate of misuse of trained words post-intervention could more closely reflect what to expect in everyday life.

Although most participants did show some misuse of words from time to time, importantly, no significant increase in misuse of trained labels was seen in either trained or untrained items following intervention. This was true both at a group level and for all nine individual participants. Only T4, the most severely impaired participant, showed any tendency towards increased misuse of trained items post-intervention, but only in response to the untrained set. Here, he made errors that included potential semantic overgeneralisations (e.g., "paper towel" in response to the pictures tea towel and serviettes) but also misuse based on initial letter (e.g., "mandarin" for microwave or "potatoes" for peanuts), and an unrelated misuse error (e.g., "chicken" for strawberries, although he recognised this as a naming error; Appendix C).

This pattern contrasts with the two individuals studied by Mayberry et al. (2011), who both showed a statistically significant rise in misuse errors after word relearning. Again, this difference in results may reflect the lack of tailoring of stimuli to participants, with the potential for differences to arise regarding the amount of semantic knowledge retained for the relearned items. In the current study, items were only included in the trained and untrained sets if at baseline the participant recognised the image and could provide some semantic information. As Mayberry et al. (2011) did not test participants' comprehension of their items, this cannot be tested directly, however, poorer semantic knowledge for the stimulus set could have resulted in reduced ability to discriminate among other items that bear visual and semantic similarities.

This preservation of semantic knowledge for target items in the current study may also explain why we did not find a clear relationship between the severity of the impairment and the rate of misuse in our participants. Although our participants had a range of severity of semantic impairment, our word lists always included some words the person could still name (cf. Hoffman et al., 2015), and only included items if the person retained some recognition of the object. This focus on vocabulary items where some knowledge was retained may have served to remove the impact of overall progression of semantic impairment

\subsection{Error profiles}

At post-intervention, few errors remained for trained items. When errors were made, they belonged to a narrower set of error types, with partially correct responses often appearing. For untrained words, the number of target attempts did not change post-intervention, but when analysed at the group level, there was evidence of a proportional increase in omissions and a proportional decrease in semantically based errors (i.e., semantic descriptions and semantic errors).

The finding that omissions were the most common error type, both at baseline and postintervention, is consistent with previous studies (Heredia et al., 2009; Hoffman et al., 2015; Woollams et al., 2008). Indeed, looking at individual participant error profiles, only two of our participants, S1 
and B1, did not have omissions as the most common error type for untrained words post-intervention. That omissions increased in the untrained list post-training may, in part, reflect the participants' experience of multiple testing of these items (at least 10 assessments by the time of the postintervention assessment). By completing multiple instances of testing, participants may have come to realise that there was one unique answer being sought for each picture in the naming assessment. This may have led to participants choosing not to produce a response when they were unable to provide the accurate label. In other contexts, this shift towards more omissions and fewer errors with semantic content might signal disease progression (as information regarding shared features continues to degrade and participants are no longer able to produce a semantically related response, resulting in omissions). However, as this intervention only spanned 4 weeks, this is unlikely to be the case here.

At an individual level, it is worth noting that while error patterns seemed to vary over time in certain participants (e.g., S1, B1, C1; visual inspection of Figure 2), the pattern of errors was highly similar across the two testing sessions for others. This is in keeping with the high consistency of responding between multiple test sessions at baseline found previously (van Scherpenberg et al., 2019).

\subsection{Clarity of response}

Increased use of omissions can have different consequences for communication, depending on exactly which type of naming error is replaced. An increase of omissions through a decrease in semantic errors could benefit communication if omissions reduce the amount of incorrect information provided (e.g., if they replace coordinate errors). However, omissions may impede communication when they replace responses that previously provided some correct semantic information regarding the target (e.g., superordinate errors, semantic descriptions). By developing a novel measure of communication clarity, we were able to examine the amount of accurate and beneficial information conveyed by each error before and after treatment to determine how changes in the error patterns may have impacted the quality of participants' responses.

Unsurprisingly, and in line with the significant training effect shown by all participants, the clarity of responses to trained items significantly improved from pre- to post-training. Of the individual participants, only G1's improvement did not reach significance (under the more conservative alpha level of .025 due to comparisons of trained and untrained items separately). For untrained items, despite the changes found in error patterns at the group level, with more omissions and fewer errors of semantic content, reassuringly the overall clarity of communication was not reduced. This is likely because the reductions in semantic component errors were balanced across some positively coded semantic responses (clarity value $=0.5$; e.g., semantic descriptions, superordinate responses/descriptions), and some negatively coded responses (clarity value $=-0.5$; e.g., coordinate responses). Importantly, this confirms that there was not a systematic shift away from providing information which benefits communication. 
Looking at individual participant results, only one (J1) showed any tendency towards decreased communication clarity on untrained items following treatment, but this was non-significant. By contrast, significant improvements in clarity were found for both G1 and S2 (although for S2, this is influenced by her attempts to train herself on some untrained words, thereby increasing her correct responses to untrained items at post-intervention). Overall, by considering the degree of beneficial information provided within an error response, it was possible to more clearly rule out hidden negative impacts of word retraining on other vocabulary.

\subsection{Practical implications}

Our key finding - that improvements in word retrieval were not accompanied by negative impacts on other vocabulary - further supports the use of word retraining programs for people with semantic dementia. From detailed analysis of naming errors, however, a couple of observations may be worth communicating to families who are interested in engaging with such programs.

Firstly, while misuse of target words may not be heightened by training, such errors will still occur from time to time for most people. It is worth advising families to be aware that while participants may now correctly make use of trained words, at least in some situations they may also retrieve these words incorrectly. In the case of compound words, it is also possible that partial retrieval may occur, resulting in odd combinations that may not have arisen previously (e.g., instead of "I don't know" an individual may produce "cutting pad" when naming the picture cutting board or say "kiwi shoes" when naming the picture kiwi fruit). Such errors and other neologistic combinations (e.g., shampoo became "hair washer" for two individuals) may be explained by novel labels being created based on remaining semantic and lexical item information when retrieval of the target name fails. Although such errors were most noticeable in those individuals with severe semantic impairment, a tendency for errors of this type was noted in a range of participants.

Secondly, as with many previous studies, we observed that benefits from word retraining therapy were item-specific, with no systematic generalisation to untrained items. Post-training, participants did not make more target attempts to untrained items or become clearer in their responses to untrained items. Thus, items to be included in training should be carefully selected to provide maximum benefit to communication in everyday living.

Finally, to facilitate individuals with semantic dementia to correctly use the trained words in their everyday lives, it is important to ensure sufficient knowledge remains for the object to be recognisable. In some instances, it may also be important to tailor training stimuli to visually match the version of the object found within a participant's home, as was done here. Where a participant may need to recognise more than one exemplar of an object, the stimuli used in training should incorporate these different exemplars. This will reduce under-generalisations by explicitly teaching the person that the label can be applied to more than one exemplar. The benefit of this practice has already been shown by Hoffman et al. (2015), where both JW and MB showed 
significantly greater ability to correctly generalise to untrained exemplars when multiple exemplars rather than a single exemplar were trained. However, Hoffman and colleagues also showed that including multiple exemplars may result in overgeneralisations for individuals with severe semantic impairment (MB in Hoffman et al., 2015). In such cases, it may be necessary to also reinforce conceptual knowledge by helping the individual to identify unique or defining features that separate the target object from semantically or visually similar objects during training.

\subsection{Limitations and Future Directions}

Although this study provides an important step forward in understanding the likelihood of misusing trained words post-intervention, there are limitations. As in previous studies, we measured the misuse of words within an artificial context of a testing session. Whether the same level of misuse would be observed in everyday living, remains unclear. Importantly though, experimental testing sessions are probably more likely to trigger such errors, given participants are repeatedly asked to recall single words from memory, in response to many pictures in a row, where items can be semantically or visually alike. The low rate in the current study is therefore reassuring, as occurrences in everyday living may be even less frequent. To confirm this, however, frequency of such errors in everyday communication should be directly addressed in future research.

We also acknowledge that given our data were not originally collected with these analyses in mind, semantic similarity and neighbourhood were not systematically manipulated in this study. Given that these may affect the probability of eliciting overgeneralisation errors, future work could specifically address these variables when constructing item lists to understand if and how these factors influence the likelihood of overgeneralisations.

Similarly, while individualised item sets align with principles of person-centred care, providing greater personal relevance and communicative value following the intervention, a drawback is the reduced ability to make direct comparison across the individuals of a case series and across studies. Such a comparison may be important to understand the differences in treatment outcomes of individuals with different disease severity. Future studies could attempt to construct a common stimulus set across participants that still only comprises items that remain meaningful for all participants. This would allow the opportunity to examine how disease severity influences rates of under and overgeneralisation errors more broadly.

On a positive note, through the creation of a simple, novel measure, we were able to evaluate how an error might impact the clarity of communication and examine performance over time. Our findings suggest that this clarity of response analysis may be a helpful addition to naming accuracy when evaluating outcomes of word retraining in participants with semantic dementia. Its application should be explored further in future research. 


\section{Summary and Conclusion}

We have reported the first study to systematically explore possible adverse effects of word retraining treatments on trained and untrained items in a relatively large series of people with semantic dementia. Training not only yielded the expected positive effects of improved naming accuracy and communication clarity for trained items, but critically, there was no evidence of negative influences from training on either trained or untrained items. While as a group, participants showed an increase in omission errors for untrained words over time, this was not associated with a change in clarity of responses compared to the baseline. This provides further encouraging evidence for the benefits of engaging people with semantic dementia in tailored word retraining programs. 
Acknowledgements: This project was made possible through the invaluable contributions of the FRONTIER research group. Original word retraining data were collected as part of a doctoral project by SAS, under the supervision of Prof John Hodges and Prof Olivier Piguet - to whom we extend our thanks. Brain imaging and broader neuropsychological data were supported by Forefront, a collaborative research group dedicated to the study of frontotemporal dementia and motor neuron disease, from the National Health and Medical research Council of Australia (NHMRC) program Grant (\#1037746). The current study was funded by a Cross Program Support Scheme grant of the Australian Research Council Centre of Excellence in Cognition and its Disorders (\#CE110001021). We would also like to acknowledge and thank the individual research participants and their families for their time and efforts in completing the word retraining program

Disclosure of interest: The authors report no conflict of interest. 


\section{References}

Agresti, A. (2002). Categorical data analysis (2nd edition). Wiley.

Beales, A., Cartwright, J., Whitworth, A., \& Panegyres, P. K. (2016). Exploring generalisation processes following lexical retrieval intervention in primary progressive aphasia. International Journal of Speech-Language Pathology, 18(3), 299-314. https://doi.org/10.3109/17549507.2016.1151936

Best, W., Nickels, L., \& Williamson, L. (2005). A coding system for picture naming responses with a focus on semantic errors. Unpublished manuscript.

Cadório, I., Lousada, M., Martins, P., \& Figueiredo, D. (2017). Generalization and maintenance of treatment gains in primary progressive aphasia (PPA): A systematic review. International Journal of Language \& Communication Disorders, 52(5), 543-560. https://doi.org/10.1111/1460-6984.12310

Carthery-Goulart, M., Silveira, A., Machado, T., Mansur, L., Parente, M., Senaha, M. L. H., Brucki, S. M. D., \& Nitrini, R. (2013). Nonpharmacological interventions for cognitive impairments following primary progressive aphasia: A systematic review of the literature. Dementia \& Neuropsychologia, 7(1), 122-131. https://doi.org/10.1590/S1980-57642013DN70100018

Croot, K. (2018). Treatment for lexical retrieval impairments in Primary Progressive Aphasia: A research update with implications for clinical practice. Seminars in Speech and Language, 39(3), 242-256. Scopus. https://doi.org/10.1055/s-0038-1660783

Croot, K., Nickels, L., Laurence, F., \& Manning, M. (2009). Impairment- and activity/participationdirected interventions in progressive language impairment: Clinical and theoretical issues. Aphasiology, 23(2), 125-160. https://doi.org/10.1080/02687030801943179

Croot, K., Raiser, T., Taylor-Rubin, C., Ruggero, L., Ackl, N., Wlasich, E., Danek, A., Scharfenberg, A., Foxe, D., Hodges, J. R., Piguet, O., Kochan, N. A., \& Nickels, L. (2019). Lexical retrieval treatment in primary progressive aphasia: An investigation of treatment duration in a heterogeneous case series. Cortex, 115, 133-158. https://doi.org/10.1016/j.cortex.2019.01.009

Croot, K., Taylor, C., Abel, S., Jones, K., Krein, L., Hameister, I., Ruggero, L., \& Nickels, L. (2015). Measuring gains in connected speech following treatment for word retrieval: A study with two participants with primary progressive aphasia. Aphasiology, 29(11), 1265-1288. https://doi.org/10.1080/02687038.2014.975181

Cumming, T. B., Graham, K. S., \& Patterson, K. (2006). Repetition priming and hyperpriming in semantic dementia. Brain and Language, 98(2), 221-234.

https://doi.org/10.1016/j.bandl.2006.05.002

Gorno-Tempini, M. L., Hillis, A. E., Weintraub, S., Kertesz, A., Mendez, M., Cappa, S. F., Ogar, J. M., Rohrer, J. D., Black, S., Boeve, B. F., Manes, F., Dronkers, N. F., Vandenberghe, R., Rascovsky, K., Patterson, K., Miller, B. L., Knopman, D. S., Hodges, J. R., Mesulam, M., \& 
Grossman, M. (2011). Classification of primary progressive aphasia and its variants. Neurology, 76(11), 1006-1014. https://doi.org/10.1212/WNL.0b013e31821103e6

Hameau, S., Biedermann, B., Fieder, N., \& Nickels, L. (2020). Investigation of the effects of semantic neighbours in aphasia: A facilitated naming study. Aphasiology, 34(7), 840-864. https://doi.org/10.1080/02687038.2019.1652241

Hameau, S., Nickels, L., \& Biedermann, B. (2019). Effects of semantic neighbourhood density on spoken word production. Quarterly Journal of Experimental Psychology, 72(12), 2752-2775. https://doi.org/10.1177/1747021819859850

Heredia, C. G., Sage, K., Lambon Ralph, M. A., \& Berthier, M. L. (2009). Relearning and retention of verbal labels in a case of semantic dementia. Aphasiology, 23(2), 192-209. https://doi.org/10.1080/02687030801942999

Hodges, J. R., Graham, N., \& Patterson, K. (1995). Charting the progression in semantic dementia: Implications for the organisation of semantic memory. Memory (Hove, England), 3(3-4), 463-495. https://doi.org/10.1080/09658219508253161

Hodges, J. R., Patterson, K., Oxbury, S., \& Funnell, E. (1992). Semantic dementia: Progressive fluent aphasia with temporal lobe atrophy. Brain, 115(6), 1783-1806. https://doi.org/10.1093/brain/115.6.1783

Hoffman, P., Clarke, N., Jones, R. W., \& Noonan, K. A. (2015). Vocabulary relearning in semantic dementia: Positive and negative consequences of increasing variability in the learning experience. Neuropsychologia, 76, 240-253. https://doi.org/10.1016/j.neuropsychologia.2015.01.015

Ikeda, M., Patterson, K., Graham, K. S., Lambon Ralph, M. A., \& Hodges, J. R. (2006). A horse of a different colour: Do patients with semantic dementia recognise different versions of the same object as the same? Neuropsychologia, 44(4), 566-575. https://doi.org/16/j.neuropsychologia.2005.07.006

Jefferies, E. (2013). The neural basis of semantic cognition: Converging evidence from neuropsychology, neuroimaging and TMS. Cortex, 49(3), 611-625. https://doi.org/10.1016/j.cortex.2012.10.008

Jefferies, E., Bott, S., Ehsan, S., \& Lambon Ralph, M. A. (2011). Phonological learning in semantic dementia. Neuropsychologia, 49(5), 1208-1218. https://doi.org/0.1016/j.neuropsychologia.2011.01.036

Jokel, R., Graham, N. L., Rochon, E., \& Leonard, C. (2014). Word retrieval therapies in primary progressive aphasia. Aphasiology, 28(8-9), 1038-1068. https://doi.org/10.1080/02687038.2014.899306

Jokel, R., Kielar, A., Anderson, N. D., Black, S. E., Rochon, E., Graham, S., Freedman, M., \& TangWai, D. F. (2016). Behavioural and neuroimaging changes after naming therapy for semantic 
variant primary progressive aphasia. Neuropsychologia, 89, 191-216.

https://doi.org/10.1016/j.neuropsychologia.2016.06.009

Jokel, R., Rochon, E., \& Anderson, N. D. (2010). Errorless learning of computer-generated words in a patient with semantic dementia. Neuropsychological Rehabilitation, 20(1), 16-41. https://doi.org/10.1080/09602010902879859

Lambon Ralph, M. A., McClelland, J. L., Patterson, K., Galton, C. J., \& Hodges, J. R. (2001). No Right to Speak? The Relationship between Object Naming and Semantic Impairment: Neuropsychological Evidence and a Computational Model. Journal of Cognitive Neuroscience, 13(3), 341-356. https://doi.org/10.1162/08989290151137395

Lambon Ralph, M. A., \& Patterson, K. (2008). Generalization and differentiation in semantic memory: Insights from semantic dementia. Annals of the New York Academy of Sciences, 1124, 61-76. https://doi.org/10.1196/annals.1440.006

Lambon Ralph, M. A., Sage, K., Jones, R. W., \& Mayberry, E. J. (2010). Coherent concepts are computed in the anterior temporal lobes. Proceedings of the National Academy of Sciences, 107(6), 2717-2722. https://doi.org/10.1073/pnas.0907307107

Lampe, L. F., Hameau, S., Fieder, N., \& Nickels, L. (2021). Effects of semantic variables on word production in aphasia. Cortex, 141, 363-402. https://doi.org/10.1016/j.cortex.2021.02.020

Lampe, L. F., Hameau, S., \& Nickels, L. (2021). Semantic variables both help and hinder word production: Behavioural evidence from picture naming. Journal of Experimental Psychology: Learning, Memory, and Cognition. https://doi.org/10.1037/xlm0001050

Mayberry, E. J., Sage, K., Ehsan, S., \& Lambon Ralph, M. A. (2011). Relearning in semantic dementia reflects contributions from both medial temporal lobe episodic and degraded neocortical semantic systems: Evidence in support of the complementary learning systems theory. Neuropsychologia, 49(13), 3591-3598. https://doi.org/10.1016/j.neuropsychologia.2011.09.010

Meyer, D., Zeileis, A., Hornik, K., Gerber, F., \& Friendly, M. (2017). vcd: Visualizing categorical data version 1.4-4 from CRAN (1.4-4) [Computer software]. https://rdrr.io/cran/ved/

Meyers, J. E., \& Meyers, K. R. (1995). Rey complex figure test and recognition trial: Professional manual. Psychological Assessment Resources, Inc.

Mioshi, E., Dawson, K., Mitchell, J., Arnold, R., \& Hodges, J. R. (2006). The Addenbrooke's Cognitive Examination Revised (ACE-R): A brief cognitive test battery for dementia screening. International Journal of Geriatric Psychiatry, 21, 1078-1085. https://doi.org/10.1002/gps. 1610

Mirman, D., \& Britt, A. E. (2014). What we talk about when we talk about access deficits. Philosophical Transactions of the Royal Society B: Biological Sciences, 369(1634), 20120388. https://doi.org/10.1098/rstb.2012.0388 
Moses, M. S., Nickels, L. A., \& Sheard, C. (2004). I'm sitting here feeling aphasic! A study of recurrent perseverative errors elicited in unimpaired speakers. Brain and Language, 89(1), 157-173. https://doi.org/10.1016/S0093-934X(03)00364-X

Moses, M. S., Sheard, C., \& Nickels, L. A. (2007). Insights into recurrent perseverative errors in aphasia: A case series approach. Aphasiology, 21(10-11), 975-1001. https://doi.org/10.1080/02687030701198312

Nelson, D. L., McEvoy, C. L., \& Schreiber, T. A. (2004). The University of South Florida free association, rhyme, and word fragment norms. Behavior Research Methods, Instruments, \& Computers, 36(3), 402-407. https://doi.org/10.3758/BF03195588

Patterson, K., Nestor, P. J., \& Rogers, T. T. (2007). Where do you know what you know? The representation of semantic knowledge in the human brain. Nature Reviews. Neuroscience, 8(12), 976-987. https://doi.org/10.1038/nrn2277

Reilly, J., Martin, N., \& Grossman, M. (2005). Verbal learning in semantic dementia: Is repetition priming a useful strategy? Aphasiology, 19(3), 329-339. https://doi.org/10.1080/02687030444000787

Ritchey, M., Libby, L. A., \& Ranganath, C. (2015). Cortico-hippocampal systems involved in memory and cognition: The PMAT framework. Progress in Brain Research, 219, 45-64. https://doi.org/10.1016/bs.pbr.2015.04.001

Rogers, T. T., Lambon Ralph, M. A., Garrard, P., Bozeat, S., McClelland, J. L., Hodges, J. R., \& Patterson, K. (2004). Structure and deterioration of semantic memory: A neuropsychological and computational investigation. Psychological Review, 111(1), 205-235. https://doi.org/10.1037/0033-295X.111.1.205

Rohrer, J. D., McNaught, E., Foster, J., Clegg, S. L., Barnes, J., Omar, R., Warrington, E. K., Rossor, M. N., Warren, J. D., \& Fox, N. C. (2008). Tracking progression in frontotemporal lobar degeneration: Serial MRI in semantic dementia. Neurology, 71(18), 1445-1451. https://doi.org/10.1212/01.wn1.0000327889.13734.cd

Rose, S. B., Aristei, S., Melinger, A., \& Abdel Rahman, R. (2019). The closer they are, the more they interfere: Semantic similarity of word distractors increases competition in language production. Journal of Experimental Psychology: Learning, Memory, and Cognition, 45(4), 753-763. https://doi.org/10.1037/xlm0000592

Rose, S. B., \& Rahman, R. A. (2017). Semantic similarity promotes interference in the continuous naming paradigm: Behavioural and electrophysiological evidence. Language, Cognition and Neuroscience, 32(1), 55-68. https://doi.org/10.1080/23273798.2016.1212081

RStudio Team. (2020). RStudio: Integrated Development for R. RStudio, PBC. http://www.rstudio.com/ 
Savage, S. A., Piguet, O., \& Hodges, J. R. (2014). Giving words new life: Generalization of word retraining outcomes in Semantic Dementia. Journal of Alzheimer's Disease: JAD, 40(2), 309317. https://doi.org/10.3233/JAD-131826

Savage, S. A., Piguet, O., \& Hodges, J. R. (2015a). Cognitive intervention in Semantic Dementia: Maintaining words over time. Alzheimer Disease and Associated Disorders, 29(1), 55-62. https://doi.org/10.1097/WAD.0000000000000053

Savage, S. A., Piguet, O., \& Hodges, J. R. (2015b). ‘Knowing what you don’t know': Language insight in Semantic Dementia. Journal of Alzheimer's Disease: JAD, 46(1), 187-198. https://doi.org/10.3233/JAD-142703

Snowden, J. S., Griffiths, H. L., \& Neary, D. (1999). The impact of autobiographical experience on meaning: Reply to Graham, Lambon Ralph, and Hodges. Cognitive Neuropsychology, 16(7), 673-687. https://doi.org/10.1080/026432999380690

Snowden, J. S., \& Neary, D. (2002). Relearning of verbal labels in semantic dementia. Neuropsychologia, 40(10), 1715-1728. https://doi.org/10.1016/S0028-3932(02)00031-3

Strauss, E., Sherman, E. M. S., \& Spreen, O. (2006). A compendium of neuropsychological tests: Administration, norms, and commentary (3rd ed.). Oxford University Press.

Suárez-González, A., Savage, S. A., \& Caine, D. (2018). Successful short-term re-learning and generalisation of concepts in semantic dementia. Neuropsychological Rehabilitation, 28(7), 1095-1109. https://doi.org/10.1080/09602011.2016.1234399

Tan, R. H., Wong, S., Kril, J. J., Piguet, O., Hornberger, M., Hodges, J. R., \& Halliday, G. M. (2014). Beyond the temporal pole: Limbic memory circuit in the semantic variant of primary progressive aphasia. Brain: A Journal of Neurology. https://doi.org/10.1093/brain/awu118

Taylor-Rubin, C., Nickels, L., \& Croot, K. (2021). Exploring the effects of verb and noun treatment on verb phrase production in primary progressive aphasia: A series of single case experimental design studies. Neuropsychological Rehabilitation, 0(0), 1-43. https://doi.org/10.1080/09602011.2021.1879174

van Scherpenberg, C., Fieder, N., Savage, S., \& Nickels, L. (2019). The relationship between response consistency in picture naming and storage impairment in people with semantic variant primary progressive aphasia. Neuropsychology, 33(1), 13-34. https://doi.org/10.1037/neu0000485

Wechsler, D. (1997). WAIS-III administration and scoring manual. The Psychological Corporation. Woollams, A. M., Cooper-Pye, E., Hodges, J. R., \& Patterson, K. (2008). Anomia: A doubly typical signature of semantic dementia. Neuropsychologia, 46(10), 2503-2514. https://doi.org/10.1016/j.neuropsychologia.2008.04.005 


\section{Appendices}

\section{Appendix A - Item details}

\section{Table A1}

Number of items in each list by participant

\begin{tabular}{cccccc}
\hline \multirow{2}{*}{ Participant } & Trained items & & \multicolumn{3}{c}{ Untrained items } \\
\cline { 2 - 2 } \cline { 5 - 6 } & List 1 & & List 2 & List 3 & \\
\hline S1 & 32 & & 32 & 32 & 96 \\
J1 & 30 & & 27 & 30 & 87 \\
S2 & 31 & & 32 & 34 & 97 \\
P1 & 32 & & 32 & 33 & 97 \\
B1 & 30 & & 32 & 33 & 95 \\
G1 & 31 & & 32 & 30 & 93 \\
J2* & 25 & & 17 & 22 & 64 \\
C1 & 38 & & 37 & 35 & 110 \\
T4 & 29 & & 31 & 40 & 100 \\
\hline
\end{tabular}

Note. * Original lists for $\mathrm{J} 2$ comprised 32 items each, however, due to technical issues in sound files, items that were incomplete or unclear were not included in the analysis. 
Table A2

Example list items (as for participant B1)

\begin{tabular}{lll}
\hline Semantic category & Trained list & Untrained list \\
\hline Food - fruit \& vegetables & grapes, nectarines, onion, & raisins, passionfruit, kiwi fruit, \\
& cucumber, broccoli, carrot & lemon, strawberries, \\
& watermelon, mandarin, \\
& tomatoes, avocado, capsicum, \\
& asparagus, cauliflower, corn, \\
& lettuce, mushrooms \\
Food - other & sausages, chocolate, tomato & steak, chicken, yoghurt, jam, \\
& mayonnaise, salt and pepper, \\
Kitchen items & juice, sugar, pasta, \\
placemats, kitchen scales, can & coasters, chopping board, grater, \\
opener, whisk, colander, & peeler, potato masher, spatula, \\
clingwrap, teapot, wine glass & tongs, ladle, dish cloth, paper \\
& towel, serviettes, pot or \\
& saucepan, frying pan, wok \\
oven, kettle, sink, vacuum & microwave, cooktop or stove, \\
cleaner, air conditioner, fan & barbecue, toaster, refrigerator or \\
& fridge, dishwasher, washing \\
& machine, heater, iron, power \\
& point, remote control, telephone \\
& or phone, computer \\
& wasp, beetle, centipede, cicada, \\
& butterfly, moth, fly, cockroach, \\
& grasshopper, praying mantis, \\
& bull ant, silverfish, snake, lizard \\
\hline
\end{tabular}




\section{Appendix B - Coding and Scoring Rules}

\section{First response and keyword coding guidelines}

- We focused on the keyword of the first response, however, only if the first response contained a target attempt

○ "oh, those little things there.... What are they called? Oh yes, bees"

$\rightarrow$ "oh, those little things there.... What are they called?" is disregarded as a comment

$\rightarrow$ "Oh yes, bees" is the first target attempt

$\rightarrow$ first keyword: "bees"

- Even a valid first response can be without target attempt

○ "I had two of them this morning"

$\rightarrow$ comment without target attempt

- Descriptions of use of an item were not coded as a target attempt

○ "a device for measuring vegetables and things like that"

$\rightarrow$ no target attempt

- Naming of superordinate category

○ "some sort of insect" and nothing else follows

$\rightarrow$ "insect" as target attempt

- "some sort of insect, I think this is a beetle"

$\rightarrow$ "some sort of insect" is disregarded as a comment

$\rightarrow$ "beetle" as target attempt

○ "some sort of insect, but I don't know which one"

$\rightarrow$ no target attempt ("some sort of insect" was not supposed to be the full response of the participant)

- Immediate self-corrections

- Describing the participant's thought process: "tissues or paper towels, I'll say paper towels"

$\rightarrow$ immediate and clear decision for "paper towel"

$\rightarrow$ "paper towel" counted as target attempt

- Change of mind: "kettle.. No! This is a coffee percolator"

$\rightarrow$ "kettle" counted as target attempt

- Negations followed by a keyword

○ "oh that's not chickens, it's something else"

$\rightarrow$ "chickens" counted as target attempt

- Incomplete first responses are disregarded 
○ "lemo... Er.. They're grapes"

$\rightarrow$ "grapes" counted as first response

- Missing or incomplete sound files in either baseline or post-test: item excluded from all analyses

\section{Perseverations}

Any full word repetitions were coded as perseveration, irrespective of their lag.

\section{Detailed error coding}

Table B1

Detailed error coding

\begin{tabular}{|c|c|c|}
\hline Error category & Subcategories & Details \\
\hline \multirow{3}{*}{ Correct } & Target response & \\
\hline & Acceptable alternative & \\
\hline & Plurals & $\begin{array}{l}\text { correct plurals: "apples" for picture apple, but not } \\
\text { "corns" for picture corn }\end{array}$ \\
\hline $\begin{array}{l}\text { Partially correct } \\
\text { response }\end{array}$ & & $\begin{array}{l}\text { - for compound nouns: response had to contain } \\
\text { one of the two nouns: "cutting pad" for picture } \\
\text { cutting board, "paper peeler" for picture potato } \\
\text { peeler or "chopping" for picture chopping board } \\
\text { - for single word items: the response had to } \\
\text { contain the target word but in combination with } \\
\text { unnecessary additional words: "baking oven" for } \\
\text { picture oven }\end{array}$ \\
\hline \multirow{3}{*}{ Semantic errors } & Coordinate & $\begin{array}{l}\text { words belonging to the same semantic category: } \\
\text { "sauce" for picture jam or "mosquito" for picture fly }\end{array}$ \\
\hline & Superordinate & $\begin{array}{l}\text { category name for the item: "vegetable" for picture } \\
\text { potato or "insect" for picture cockroach }\end{array}$ \\
\hline & Associate & $\begin{array}{l}\text { related words as found in the Nelson et al. (2004) } \\
\text { association norms: "salt" for picture peanuts or } \\
\text { "birthday" for picture cake }\end{array}$ \\
\hline $\begin{array}{l}\text { Semantic } \\
\text { descriptions }\end{array}$ & $\begin{array}{l}\text { Semantically based } \\
\text { descriptions }\end{array}$ & $\begin{array}{l}\text { responses which provide some correct semantic } \\
\text { information regarding the item, including } \\
\text { - descriptions of major use: "a device for } \\
\text { measuring vegetables and things like that" for } \\
\text { picture kitchen scale }\end{array}$ \\
\hline
\end{tabular}




\begin{tabular}{ll}
\hline- & description of how the item is used/words which \\
& describe the main action carried out with the \\
& item: "scraper" for picture rake, "ironing" for \\
& picture iron \\
- & description of what it is similar to: "little kitchen \\
& towel" for picture dish cloth \\
- & description of kind/consistency: "creamy item" \\
& for picture mayonnaise, "little crunchy things" \\
& for picture peanuts \\
& any multi-word response that includes a \\
& superordinate as the keyword: "some sort of insect, \\
& but I don't know which one" for picture fly, "another \\
Superordinate & vegetable" for picture carrot, "cooking item" for \\
description & picture wok
\end{tabular}

\begin{tabular}{|c|c|c|}
\hline \multirow{3}{*}{$\begin{array}{l}\text { Non-semantic } \\
\text { descriptions }\end{array}$} & \multicolumn{2}{|l|}{ Episodic memory } \\
\hline & \multirow{2}{*}{\multicolumn{2}{|c|}{$\begin{array}{l}\text { Orthographic } \\
\text { description }\end{array}$}} \\
\hline & & \\
\hline \multirow{16}{*}{ Other errors } & \multicolumn{2}{|l|}{ Unrelated real words } \\
\hline & \multicolumn{2}{|l|}{ Incorrect superordinate } \\
\hline & \multirow{10}{*}{ Other descriptions } & - visual description: "top of oven" for picture \\
\hline & & stove \\
\hline & & - neutral (vague or non-specific information): \\
\hline & & "little guys" for picture mosquito, "in the \\
\hline & & kitchen" for picture bowl \\
\hline & & - neologistic or incorrect with target relationship: \\
\hline & & "baking parts of baking table" for picture stove, \\
\hline & & "for boiling water" for picture teapot \\
\hline & & - incorrect without target relationship: "you can \\
\hline & & use it for striking” for picture peeler \\
\hline & $\begin{array}{l}\text { Nonword } \\
\text { (phonologically related } \\
\text { and unrelated) }\end{array}$ & $\begin{array}{l}\text { phonologically related nonword: "scaptula" for } \\
\text { picture spatula }\end{array}$ \\
\hline & Morphological & \\
\hline & neologism & \\
\hline & Visual error & $\begin{array}{l}\text { no semantic connection between item and response: } \\
\text { "snake" for picture belt }\end{array}$ \\
\hline
\end{tabular}


- "I don't know" or "not sure about that one" note the exception: in response "I don't know... maybe a cat", "maybe a cat" is coded as the

Omissions response and the initial "I don't know" disregarded as a comment

- null responses: no response or "um..."

- time out: no response within 10 seconds

\section{Clarity of responses coding}

\section{Table B2}

Clarity of response scoring

\begin{tabular}{|c|c|}
\hline $\begin{array}{l}\text { Numeric } \\
\text { score }\end{array}$ & Response type \\
\hline 1 & $\begin{array}{l}\text { correct name is given } \\
-\quad \text { target response } \\
-\quad \text { acceptable alternatives } \\
-\quad \text { plurals }\end{array}$ \\
\hline 0.5 & 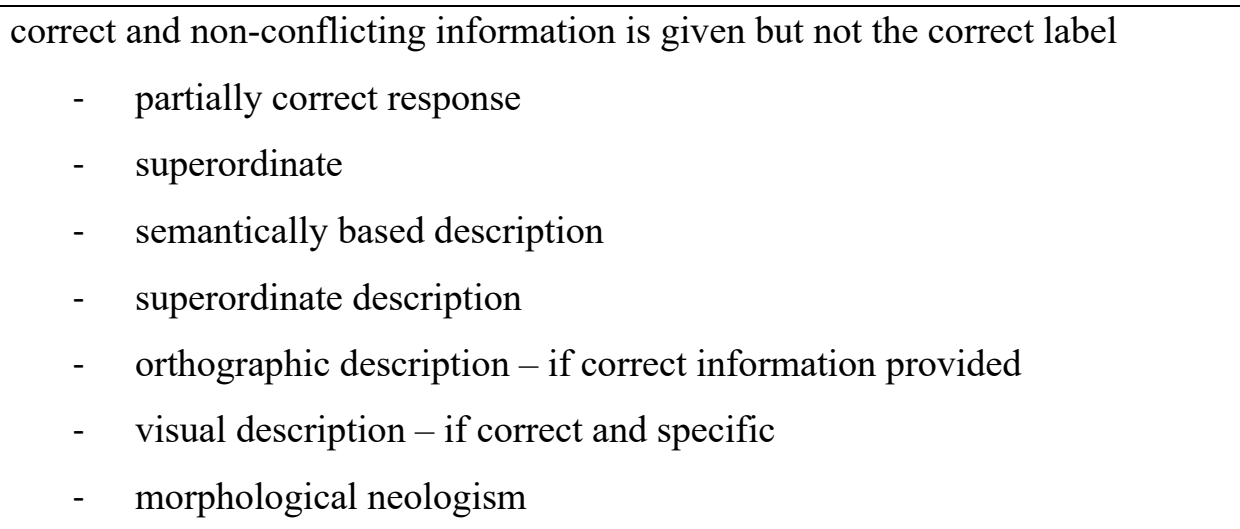 \\
\hline 0 & $\begin{array}{ll}\text { non-specific responses } \\
- & \text { episodic memory } \\
- & \text { omission } \\
\text { - } & \text { other description - neutral content (neither clearly correct nor incorrect, } \\
& \text { including a mix of content) }\end{array}$ \\
\hline-0.5 & $\begin{array}{l}\text { associated, but incorrect information is provided } \\
\text { - } \text { associate } \\
\text { - } \quad \text { coordinate }\end{array}$ \\
\hline
\end{tabular}


- other description - neologistic or incorrect content but with a close relationship to the target

\begin{aligned} & \hline$-1 \quad$ incorrect and unrelated or misleading information is provided \\ &- unrelated real word \\ &- incorrect superordinate \\ &- other description - incorrect content (description is clearly unrelated or \\ & misleading) \\ &- orthographic description -incorrect content without target relationship \\ &- nonword (phonologically related and unrelated) \\ &- visual error \\ & \hline\end{aligned}




\section{Appendix C - Instances of misuse}

\section{Table C1}

Instances of misuse of list items pre- and post-intervention by participant

\begin{tabular}{|c|c|c|c|c|c|}
\hline & $\begin{array}{l}\text { Trained targets named using other } \\
\text { trained words } \\
\text { BL } \\
\text { Target word } \rightarrow \\
\text { response given } \quad \text { Post } \\
\end{array}$ & \multicolumn{2}{|c|}{ Untrained targets named using trained words } & \multicolumn{2}{|c|}{ Repetition errors across all lists } \\
\hline S1 & & $\begin{array}{l}\text { Clarinet } \rightarrow \text { trumpet } \\
\text { Coriander } \rightarrow \text { parsley }\end{array}$ & $\begin{array}{l}\text { Cockroach } \rightarrow \text { spider } \\
\text { Coriander } \rightarrow \text { parsley } \\
\text { Saxophone } \rightarrow \\
\text { trumpet }\end{array}$ & $\begin{array}{l}\text { Cello } \rightarrow \text { big violin (63) } \\
\text { Clarinet } \rightarrow \text { trumpet (2) } \\
\text { Cockroach } \rightarrow \text { beetle } \\
(30) \\
\text { Coriander } \rightarrow \text { parsley } \\
(22) \\
\text { Ladybird } \rightarrow \text { beetle }(47)\end{array}$ & $\begin{array}{l}\text { Cockroach } \rightarrow \text { spider }(23) \\
\text { Coriander } \rightarrow \text { parsley }(33)\end{array}$ \\
\hline $\mathrm{J} 1$ & $\begin{array}{l}\text { Ladybird } \rightarrow \text { beetle } \\
\text { Mosquito } \rightarrow \text { spider }\end{array}$ & Killer whale $\rightarrow$ dolphin & $\begin{array}{l}\text { Killer whale } \rightarrow \\
\text { dolphin } \\
\text { Kookaburra } \rightarrow \\
\text { cockatoo } \\
\text { Noisy miner } \rightarrow \text { Indian } \\
\text { myna }\end{array}$ & $\begin{array}{l}\text { Killer whale } \rightarrow \text { dolphin } \\
(51) \\
\text { Pigeon } \rightarrow \text { dove }(62)\end{array}$ & $\begin{array}{l}\text { Kookaburra } \rightarrow \text { cockatoo } \\
\text { (43) }\end{array}$ \\
\hline
\end{tabular}




\begin{tabular}{|c|c|c|c|c|c|c|}
\hline B1 & & & $\begin{array}{l}\text { Wasp } \rightarrow \text { mosquito }(\rightarrow \\
\text { "another insect") }\end{array}$ & Fly $\rightarrow$ bee & $\begin{array}{l}\text { Beetle } \rightarrow \text { cockroach } \\
(88) \\
\text { Grasshopper } \rightarrow \text { cocky } \\
(47) \\
\text { Frying pan } \rightarrow \text { pot }(34)\end{array}$ & $\begin{array}{l}\text { Frying pan } \rightarrow \text { saucepan } \\
(59)\end{array}$ \\
\hline G1 & & $\begin{array}{l}\text { Steak } \rightarrow \text { silver } \\
\text { beet [self- } \\
\text { corrected "no"] } \\
\text { (silver beet } \rightarrow \\
\text { blue...) }\end{array}$ & $\begin{array}{l}\text { Dishwasher } \rightarrow \text { washing } \\
\text { machine }\end{array}$ & $\begin{array}{l}\text { Teapot } \rightarrow \text { tea jug } \\
\text { Toaster } \rightarrow \text { milk }\end{array}$ & $\begin{array}{l}\text { Dishwasher } \rightarrow \text { washing } \\
\text { machine }(23) \\
\text { Teapot, coaster } \rightarrow \text { cup } \\
(-54 ;-44)\end{array}$ & $\begin{array}{l}\text { Teapot } \rightarrow \text { jug }(51) \\
\text { Toaster } \rightarrow \text { milk }(41)\end{array}$ \\
\hline \multicolumn{7}{|l|}{$\mathrm{J} 2$} \\
\hline $\mathrm{C} 1$ & $\begin{array}{l}\text { Tea towel } \rightarrow \text { towel } \\
\text { ("another towel") }\end{array}$ & $\begin{array}{l}\text { Rubber band } \rightarrow \\
\text { button }\end{array}$ & $\begin{array}{l}\text { Dish cloth } \rightarrow \text { towel } \\
\text { ("another towel") } \\
\text { Dishwasher } \rightarrow \text { washing } \\
\text { machine } \\
\text { Teapot } \rightarrow \text { kettle ( } \rightarrow \\
\text { description of use) }\end{array}$ & $\begin{array}{l}\text { Dish cloth } \rightarrow \text { towel } \\
\text { Peas } \rightarrow \text { button }\end{array}$ & $\begin{array}{l}\text { Dish cloth } \rightarrow \text { towel }(6) \\
\text { Frying pan } \rightarrow \text { pot }(46) \\
\text { Polo shirt } \rightarrow \text { shirt }(18) \\
\text { Tea towel } \rightarrow \text { towel }(52)\end{array}$ & Peas $\rightarrow$ buttons (3) \\
\hline $\mathrm{T} 4$ & $\begin{array}{l}\text { Serviettes } \rightarrow \text { paper } \\
\text { towel }\end{array}$ & & & $\begin{array}{l}\text { Microwave } \rightarrow \\
\text { mandarin } \\
\text { Peanuts } \rightarrow \text { potatoes } \\
\text { Shower } \rightarrow \text { sink } \\
\text { Strawberries } \rightarrow \\
\text { chicken } \\
\text { Tea towel } \rightarrow \text { paper } \\
\text { towel }\end{array}$ & $\begin{array}{l}\text { Dishwasher } \rightarrow \text { washing } \\
\text { machine }(51) \\
\text { Singlet, t-shirt } \rightarrow \text { shirt } \\
(-42 ;-23)\end{array}$ & $\begin{array}{l}\text { Banana } \rightarrow \text { apple (24) } \\
\text { Microwave } \rightarrow \text { mandarin } \\
(9) \\
\text { Shower } \rightarrow \text { sink (2) } \\
\text { Strawberries } \rightarrow \text { chicken } \\
(10) \text { [error acknowledged: } \\
\text { "not chicken"] } \\
\text { Socks, trousers } \rightarrow \text { shirt } \\
(-79 ;-16)\end{array}$ \\
\hline $\begin{array}{l}\text { Grand } \\
\text { Total }\end{array}$ & 4 & 2 & 13 & 20 & 21 & 13 \\
\hline
\end{tabular}

Note. Words that are written in bold were named correctly when they appeared as target words. 